\title{
Evaluation of large-eddy simulations forced with mesoscale model output for a multi-week period during a measurement campaign
}

\author{
Rieke Heinze $^{1,2}$, Christopher Moseley ${ }^{1}$, Lennart Nils Böske ${ }^{2}$, Shravan Kumar Muppa ${ }^{3}$, Vera Maurer ${ }^{4,5}$, \\ Siegfried Raasch ${ }^{2}$, and Bjorn Stevens ${ }^{1}$ \\ ${ }^{1}$ Atmosphäre im Erdsystem, Max-Planck-Institut für Meteorologie, Hamburg, Germany \\ ${ }^{2}$ Institut für Meteorologie und Klimatologie, Leibniz Universität Hannover, Hanover, Germany \\ ${ }^{3}$ Institut für Physik und Meteorologie, Universität Hohenheim, Stuttgart, Germany \\ ${ }^{4}$ Institut für Meteorologie und Klimaforschung - Department Troposphärenforschung, Karlsruhe Institut für Technologie, \\ Karlsruhe, Germany \\ ${ }^{5}$ Klima- und Umweltberatung, Deutscher Wetterdienst, Offenbach, Germany \\ Correspondence to: Rieke Heinze (rieke.heinze@mpimet.mpg.de)
}

Received: 10 June 2016 - Discussion started: 14 June 2016

Revised: 27 April 2017 - Accepted: 12 May 2017 - Published: 15 June 2017

\begin{abstract}
Large-eddy simulations (LESs) of a multi-week period during the $\mathrm{HD}(\mathrm{CP})^{2}$ (High-Definition Clouds and Precipitation for advancing Climate Prediction) Observational Prototype Experiment (HOPE) conducted in Germany are evaluated with respect to mean boundary layer quantities and turbulence statistics. Two LES models are used in a semi-idealized setup through forcing with mesoscale model output to account for the synoptic-scale conditions. Evaluation is performed based on the HOPE observations. The mean boundary layer characteristics like the boundary layer depth are in a principal agreement with observations. Simulating shallow-cumulus layers in agreement with the measurements poses a challenge for both LES models. Variance profiles agree satisfactorily with lidar measurements. The results depend on how the forcing data stemming from mesoscale model output are constructed. The mean boundary layer characteristics become less sensitive if the averaging domain for the forcing is large enough to filter out mesoscale fluctuations.
\end{abstract}

\section{Introduction}

Large-eddy simulation (LES) studies have usually focused on a specific atmospheric boundary layer type, often with the purpose of addressing a specific theoretical question. Many early atmospheric LESs initially focused on cloud-free, con- vective boundary layers (e.g., Deardorff, 1970b, 1972; Moeng, 1984). Later, various studies additionally investigated the effects of wind shear on the convective boundary layer (e.g., Mason, 1992; Moeng and Sullivan, 1994). The role of clouds in the dynamics of the boundary layer has motivated more sophisticated LESs of cloud-topped boundary layers. Stratus and stratocumulus clouds have been considered in numerous works (e.g., Deardorff, 1976, 1980; Moeng, 1986; Stevens et al., 1998) and shallow-cumulus clouds have also been successfully simulated (e.g., Sommeria, 1976; Cuijpers and Duynkerke, 1993; Brown et al., 2002; Siebesma et al., 2003). Less attention has been paid to stably stratified boundary layers because their simulation requires even higher resolutions and computer resources (compared to LESs of convective situations) as the stable boundary layers are usually very shallow. Furthermore, turbulence in the stable layers is usually intermittent and coupled to waves. Nonetheless, there are several LESs and direct numerical simulation studies of the stable boundary layer (e.g., Mason and Derbyshire, 1990; Saiki et al., 2000; Beare et al., 2006; Edwards et al., 2014; Ansorge and Mellado, 2014, 2016). There are other studies investigating the diurnal transition between different boundary layer types (e.g., Nieuwstadt and Brost, 1986; Sorbjan, 1997; van Stratum and Stevens, 2015).

In reality, however, different types of the atmospheric boundary layer occur consecutively if longer time periods spanning weeks to months and even years are considered. 
LESs of these longer time periods (called long-term LESs in the following) became computationally tractable through massively parallel codes and advances in computing (Schalkwijk et al., 2012, 2015). What benefits and new insights can be gained from the long-term LES approach compared to previous studies? First of all, LES models can be regarded as virtual laboratories, in which the characteristics of atmospheric microscale flows can be studied and understood under controlled conditions (Neggers et al., 2012). One major practical benefit from LES is the development and improvement of boundary layer parameterization schemes (e.g., Noh et al., 2003). By testing parameterization schemes with a multitude of different boundary layer situations (including transitions), the tuning towards special atmospheric conditions, which might not even be representative, can be avoided (Neggers et al., 2012). Furthermore, realistic long-term turbulence data sets are also of great interest in other fields of study, especially those with a high practical orientation (e.g., studies concerning wind energy (Vollmer et al., 2015) or air quality and ventilation effects in urban environments).

When focusing on LESs longer than several hours, the importance of including synoptic-scale meteorological conditions in LESs increases. Larger-scale forcing in terms of time-varying horizontal and vertical advective tendencies as well as larger-scale pressure gradients (geostrophic wind) should be prescribed to account for the overall larger-scale conditions. The strategy to prescribe larger-scale forcing terms has been applied in various single-column and LES studies (e.g., Randall and Cripe, 1999). Even early LES case studies (e.g., Sommeria, 1976) included synoptic-scale forcing. For idealized LES case studies focusing on a specific boundary layer type, the larger-scale forcing is usually constructed based on observations from measurement campaigns (e.g., Siebesma et al., 2003; Stevens et al., 2005). Synopticscale forcing can also be obtained from larger-scale models (e.g., Neggers and Siebesma, 2013) or a combination of observations and models (e.g., Baas et al., 2010; vanZanten et al., 2011; Pietersen et al., 2015). Regarding long-term simulations in the semi-idealized setup, relaxation towards a reference state given by a larger-scale model or observations can be used in combination with advective forcing to prevent model drift in time (Neggers et al., 2012).

In this study LESs covering almost 3 weeks (19 days) of the $\mathrm{HD}(\mathrm{CP})^{2}$ (High-Definition Clouds and Precipitation for advancing Climate Prediction) Observational Prototype Experiment (HOPE; Macke et al., 2017) are evaluated by comparing the results with the multi-sensor HOPE data set specifically designed with this purpose in mind. Particularly, the simultaneous operation of several new lidar systems during HOPE provided the unique opportunity to study planetary boundary layer characteristics with unprecedented detail. The importance of high-resolution thermodynamic profiling for model evaluation is also outlined in Wulfmeyer et al. (2015). Results of a year-long LES centered at a meteorological observational supersite were presented by Schalk- wijk et al. (2015). They followed a statistical approach to assessing the quality of their long-term LES by comparing yearly-averaged diurnal cycles and climatologies with those from observations and concluded that the semi-idealized approach is stable enough to simulate a whole year of varying conditions. The present study focuses on a day-to-day comparison with observations from a measurement campaign, which also accounts for spatial variability by providing measurements at three different principal measurement sites. Here, we want to tackle the question of if the longterm LES approach is able to deliver a realistic boundary layer representation. In this regard, the study is one of the first approaches to allow for a direct comparison of LESs to measurements for a period longer than several days. Furthermore, the study can serve as a basis for understanding the role of the mesoscale by comparing results of LES in a limitedarea setup (where, for example, orography and surface heterogeneity are considered, as in Heinze et al., 2017) with the LESs in the semi-idealized setup presented here.

To asses how representative and robust the results of the present study are, two strategies are followed. One strategy is to use two well-established LES models instead of just one. Applying two LES models provides a measure for the variability among the LESs - comparable to assessing observations of one quantity from multiple sensors. The other strategy is to study how the results depend on details of the setup. As the long-term LES approach relies on prescribing larger-scale forcing it is important to know how sensitive the LES results are with respect to details of the forcing like the calculation of the larger-scale advective tendencies from the mesoscale model or the relaxation (nudging) to the mesoscale model. Furthermore, this gives us the opportunity to assess the extent to which mesoscale variability plays a role in determining boundary layer characteristics.

This study also has some relevance for using 3-D LESs in the form of a superparameterization in large-scale (global) models as proposed by Grabowski (2016). In this approach, an LES model is embedded in each column of the large-scale model with horizontal grid lengths of the order of $10-50 \mathrm{~km}$ to account for an improved representation of small-scale processes in global models. In each global model grid box, one LES runs on a separate core of a massive parallel computer and communicates with the global model by exchanging only mean profiles during the simulation. The long-term LES approach under investigation would be representative for the superparameterization of one global model grid box.

Note that the LES statistics in this semi-idealized setup with prescribed forcing can only provide a mean over a certain representative area. The measurements, however, are exposed to spatial variability, and a point measurement at a certain location is only a local sample. As measurements from all available HOPE-sites are used for the comparison between the LESs and observations, a certain degree of variability can be expected in the measurements and compared to LESs. In this sense we expect that a fair comparison between 
observations and the LESs is possible and that the measurements inform what should be expected to be seen in the representative LESs.

The paper is organized as follows. Section 2 provides a description of the LES models applied and of the setup. The relative importance of the larger-scale forcing terms is also assessed. Section 3 gives an overview of the measurement campaign HOPE and of the observations used in this study. In Sect. 4 the 19-day reference simulation is analyzed. First (Sect. 4.1), the temporal evolution of key boundary layer quantities is discussed. Next (Sect. 4.2), vertical profiles of second-moment turbulent quantities for a cloud-free and a shallow-cumulus case are compared with profiles obtained from lidar. In Sect. 5, the results of various sensitivity runs are presented. Summary and conclusions are presented in Sect. 6.

\section{Large-eddy simulations}

\subsection{Large-eddy models}

Two well-established LES models, PALM (PArallelized Large-eddy simulation Model 4.0, revision 1574, https:// palm.muk.uni-hannover.de; Maronga et al., 2015) and the UCLA-LES (University of California, Los Angeles largeeddy simulation model; Stevens et al., 2005), are used in the present study. Both finite-difference models solve the same set of implicitly filtered, incompressible, non-hydrostatic Navier-Stokes equations including the three velocity components $u, v$ and $w$ and the perturbation pressure $p$ as well as the transport equations for liquid water potential temperature $\theta_{\mathrm{l}}$, total water mixing ratio $q_{\mathrm{t}}$, rainwater mixing ratio $q_{\mathrm{r}}$ and number concentration $N_{\mathrm{r}}$ on a staggered, C-type (Harlow and Welch, 1965; Arakawa and Lamb, 1977) Cartesian grid. The major differences between the two models are listed below.

1. In PALM the shallow-convection approximation (Dutton and Fichtl, 1969) is used where the reference density is constant. UCLA-LES solves the equations in the less constrained anelastic approximation (Ogura and Phillips, 1962) allowing for a varying reference density with height.

2. Sub-grid-scale (SGS) turbulence closure is prognostic in PALM by solving the equation for the SGS turbulence kinetic energy according to Deardorff (1980) and diagnostic in UCLA-LES using a classical Smagorinsky (1963) scheme.

3. PALM uses a fifth-order advection scheme based on Wicker and Skamarock (2002) for both momentum and scalars. In UCLA-LES a fourth-order central advection scheme is applied for momentum and a monotone second-order scheme with a flux limiter for scalars.
4. PALM includes a Lagrangian cloud model and was often used in studies discussing shallow convection (e.g., Riechelmann et al., 2015; Hoffmann et al., 2015; Hoffmann, 2016). UCLA-LES incorporates a hierarchy of microphysical models and representations of radiative transfer and was applied in studies focusing more on deep convection (e.g., Rieck et al., 2015; Schlemmer and Hohenegger, 2016).

PALM and UCLA-LES both apply the fractional-step method to ensure incompressibility of the flow, and the resulting Poisson equation for the perturbation pressure is solved by a fast Fourier transform. In the simulations presented here, the cloud water mixing ratio $q_{\mathrm{c}}$ is obtained via the simple saturation-adjustment scheme in both models. The warm microphysics scheme of Seifert and Beheng (2001, 2006) and Seifert (2008) is applied and Monin-Obukhov similarity theory is used at the surface. A no-slip condition is applied to the horizontal velocity components at the surface. The horizontal boundaries are cyclic and both models use a third-order Runge-Kutta method with a variable time step to advance in time. The parallelization method follows a 2-D domain decomposition using Message Passing Interface for inter-process communication.

\subsection{Forcing with mesoscale model output}

To account for synoptic-scale forcing, the effects of largerscale pressure gradients, horizontal advection and vertical motions have to be prescribed in LESs. However, the usage of lateral periodic boundary conditions constrains how the synoptic scales can be represented. As horizontal LES domain-scale gradients cannot be represented, larger-scale advection, pressure gradients and vertical motions are assumed to be horizontally homogeneous, but they may vary in time and height. This approach has direct implications on how larger-scale phenomena can be represented in the LES, for instance frontal passages. In the presence of a front, the flow field exhibits strong local gradients perpendicular to the front. However, in the LES, a front would simultaneously arrive and depart from the entire domain at a specific height due to the periodic boundary conditions. Thus, the evolution of frontal passages is represented in time rather than in space (Schalkwijk et al., 2015).

Time-dependent surface conditions, which are representative for the entire LES domain, are required. To facilitate the comparison between the two LES models, surface values are prescribed instead of using a land-surface model.

The larger-scale forcing can be generated from 3-D output of a larger-scale (global or limited area) climate or numerical weather prediction model (e.g., Neggers and Siebesma, 2013). Creating larger-scale forcing solely from measurements is also possible (e.g., Grabowski et al., 1996), or a combination (blending) of a larger-scale model and observations can be applied (e.g., Baas et al., 2010; Bosveld et al., 2014). Here, the forcing is calculated from analysis output 
of the operational mesoscale numerical weather prediction model COSMO-DE (denoted as COSMO hereinafter Baldauf et al., 2011). The COSMO analysis is thought to provide a good estimate of a current state as it is a combination of model output and assimilated measurements. COSMO is also denoted as the host model in the following.

The larger-scale tendencies for the governing equations can be derived formally by decomposing the variables into larger-scale and turbulence-scale components where the larger-scale component is further decomposed into a horizontally averaged part and a space-dependent part. The latter is then neglected, which can be justified by a scale analysis. A detailed description of this methodology for using larger-scale forcing in a cloud-resolving model is given by Grabowski et al. (1996).

The calculation of the larger-scale tendencies in the LES is provided in the following. The effect of the larger-scale pressure gradient (LSP) enters the horizontal momentum equations:

$$
\left.\frac{\partial u_{i}}{\partial t}\right|_{\mathrm{LSP}}=\varepsilon_{i 3 j} f_{3} u_{\mathrm{g}, j},
$$

where $u_{\mathrm{g}, i}=\left(u_{\mathrm{g}, 1}, u_{\mathrm{g}, 2}, 0\right)$ denotes the geostrophic wind vector, which is calculated by means of the largerscale pressure $\left(p_{\mathrm{LS}}\right)$ gradients and density $\left(\rho_{\mathrm{LS}}\right)$ as $u_{\mathrm{g}, 1}=-\left(\rho_{\mathrm{LS}} f_{3}\right)^{-1} \partial p_{\mathrm{LS}} / \partial x_{2}, \quad u_{\mathrm{g}, 2}=\left(\rho_{\mathrm{LS}} f_{3}\right)^{-1} \partial p_{\mathrm{LS}} / \partial x_{1}$ and $u_{\mathrm{g}, 3}=0$. Einstein summation convention for repeated indices is used. $f_{i}=(0,2 \Omega \cos (\phi), 2 \Omega \sin (\phi))$ denotes the Coriolis parameter, where $\Omega$ is the angular speed of the Earth and $\phi$ is the geographical latitude.

The contributions due to larger-scale horizontal advection (LSA) and vertical advection (subsidence, SUB) enter the scalar prognostic equations only:

$$
\begin{aligned}
& \left.\frac{\partial \varphi}{\partial t}\right|_{\mathrm{LSA}}=-\left(u_{\mathrm{LS}, 1} \frac{\partial \varphi_{\mathrm{LS}}}{\partial x_{1}}+u_{\mathrm{LS}, 2} \frac{\partial \varphi_{\mathrm{LS}}}{\partial x_{2}}\right), \\
& \left.\frac{\partial \varphi}{\partial t}\right|_{\mathrm{SUB}}=-u_{\mathrm{LS}, 3} \frac{\partial \varphi}{\partial x_{3}} \text { with } \varphi \in\left\{\theta_{\mathrm{l}}, q_{\mathrm{t}}\right\} .
\end{aligned}
$$

All three larger-scale velocity components $u_{\mathrm{LS}, i}$ and scalar components $\varphi_{\text {LS }}$ are needed. Note that the LSA contribution (Eq. 2) is horizontally homogeneous, whereas the SUB contribution (Eq. 3) is not. Here, the horizontal homogeneous subsidence velocity $u_{\mathrm{LS}, 3}=w_{\mathrm{SUB}}$ is combined with the local gradient of the LES scalar $\varphi$. This ensures that the tendencies are strongest where the local scalar gradients are largest and $w_{\text {SUB }}$ is not negligible (which is usually at the top of the boundary layer).

The simulations presented in this study use Newtonian relaxation (nudging) in addition to the previously discussed larger-scale components. The main function of nudging in the larger-scale forcing framework is to prevent excessive model drift in time (Neggers et al., 2012). This drift may be introduced by errors in the LES or by systematic errors in the larger-scale forcing terms. By means of nudging, the simulated flow is adjusted to the flow situation of the host model
(Anthes, 1974; Stauffer and Bao, 1993). This is an additional possibility to account for larger-scale processes in an LES. However, relaxation has to be handled with care since it represents no real physical process (Randall and Cripe, 1999). To preserve turbulent structures, the applied nudging tendency is horizontally homogeneous in analogue to the LSP and LSA tendencies and it is given by

$\left.\frac{\partial \varphi}{\partial t}\right|_{\mathrm{NUD}}=-\frac{\langle\varphi\rangle-\varphi_{\mathrm{LS}}}{\tau}$ with $\varphi \in\left\{u, v, \theta_{\mathrm{l}}, q_{\mathrm{t}}\right\}$,

where the angle brackets $(\langle\ldots\rangle)$ denote the horizontal average of the LES variable and $\tau$ is the relaxation timescale, which defines the strength of the nudging. With a small $\tau$, the horizontal averages of the prognostic variables are adjusted relatively fast towards the corresponding state of the host model. A nudging timescale of $\tau=6 \mathrm{~h}$ is used, which is long enough for the fast boundary layer physics to develop their own unique state and short enough so that larger-scale disturbances, such as weather fronts, can be represented in the LES (Neggers et al., 2012; Schalkwijk et al., 2015).

The larger-scale tendency terms (Eqs. 1-4) are calculated from the operational COSMO analysis data, which have a horizontal and temporal resolution of $2.8 \mathrm{~km}$ and $3 \mathrm{~h}$, respectively. Thus, the larger-scale forcing terms used in this study do not stem from pure model output as the analysis is composed of a combination of model output and assimilated measurements. It should be noted that the larger-scale tendencies should not contain any impacts of small-scale phenomena, which are explicitly resolved by the LES. Thus, the COSMO data are averaged spatially to filter out these scales. The averaging procedure is further described in Appendix A. The resulting larger-scale forcing profiles are linearly interpolated in time between every $3 \mathrm{~h}$ to obtain a forcing at every time step in the LES.

\subsection{Setup}

The reference simulation performed with both models (denoted as RP and RU for PALM and UCLA-LES, respectively) consists of a continuous 19-day simulation covering 24 April to 12 May 2013 over the HOPE region. An isotropic grid spacing of $\Delta=50 \mathrm{~m}$ is used up to a height of $5 \mathrm{~km}$ above ground. Above $5 \mathrm{~km}$, vertical grid stretching is applied, resulting in a model top of about $13 \mathrm{~km}$. Note that due to the underlying assumption of incompressibility in the set of model equations, the results above a height of approximately $5 \mathrm{~km}$ should be interpreted with care, especially for PALM due to the shallow-convection approximation used. A model top of $13 \mathrm{~km}$ is chosen nonetheless, as then the evolution of the prognostic variables above a certain height can be almost entirely ascribed to the larger-scale and deepconvective events in the forcing and may find some representation in the LES. The horizontal extension of the modeling domain is $48 \mathrm{~km} \times 48 \mathrm{~km}$. In total, the model domain is resolved by $960 \times 960 \times 144$ grid cells. Figure 1a shows the 

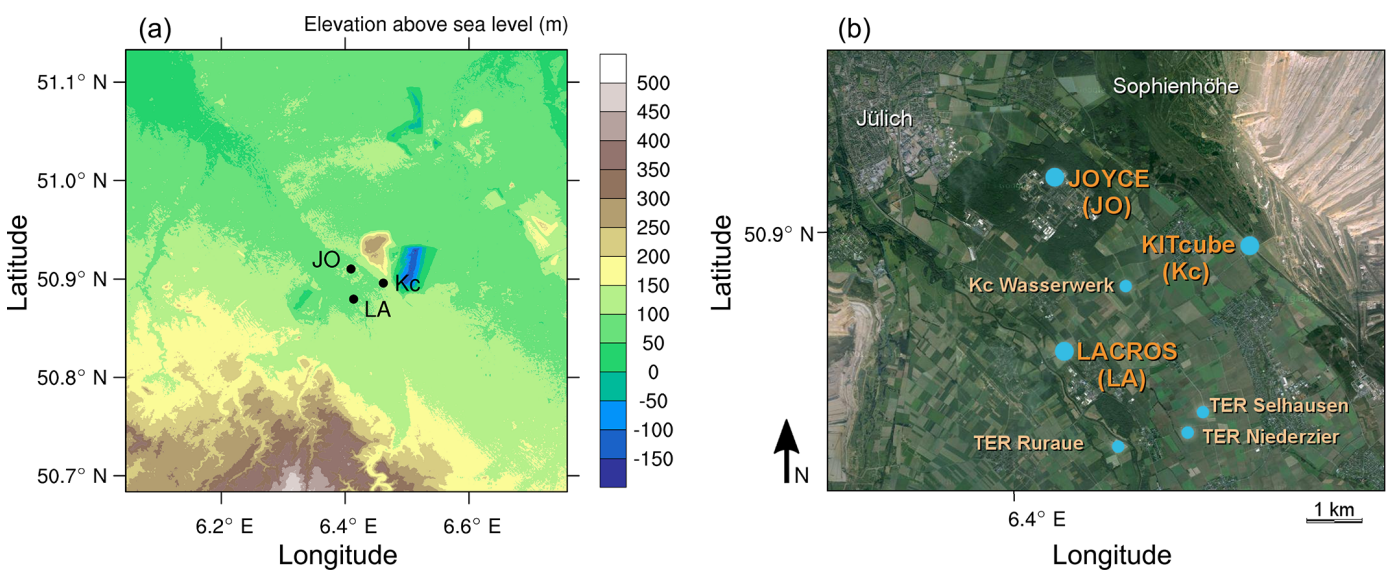

Figure 1. Location of different measurement sites during the HOPE campaign. The abbreviations JOYCE (JO), LACROS (LA) and KITcube $(\mathrm{Kc})$ denote the three principal measurement sites Jülich Observatory for Cloud Evolution, Leipzig Aerosol and Cloud Remote Observations System, and the Karlsruhe Institute of Technology cube, respectively. Panel (a) shows the topography in a $50 \mathrm{~km} \times 50 \mathrm{~km}$ domain centered around JOYCE (source: ASTER GDEM Validation Team (2011)) and (b) provides a closer view of the HOPE measurement sites (source: Google Maps). Additional surface flux measurements were taken at the Kc site Wasserwerk (Kc Was) and the TERENO (TER) sites Ruraue (TER Rur), Selhausen (TER Sel) and Niederzier (TER Nied).

topography in a $50 \mathrm{~km} \times 50 \mathrm{~km}$ domain around the central HOPE region. Apart from the Eifel mountain range in the southwest of the region, the domain is rather flat, which is reflected by using a flat homogeneous surface in the LES.

As explained in Sect. 2.4 and Appendix A, the larger-scale forcing data are constructed by averaging COSMO analysis data. The center of the averaging domain is located at $6.375^{\circ} \mathrm{E}$ and $50.875^{\circ} \mathrm{N}$, which is centered in the HOPE region (see Sect. 3). The larger-scale forcing data are averaged over a domain with the size of $2.0^{\circ} \times 2.0^{\circ}$ on the geographical grid $(80 \times 80$ COSMO grid points) to eliminate smallscale fluctuations. This corresponds to a zonal and meridional extension of the averaging domain of 140 and $222 \mathrm{~km}$, respectively. The latitude is set to $\phi=50.92^{\circ}$ to define the Coriolis parameter for the HOPE region. At the surface, temperature and humidity are prescribed horizontally homogeneous (Dirichlet conditions). The roughness length $z_{0}$ for momentum is adopted from the averaged COSMO data and thus depends on the chosen averaging domain. It results in a value of $z_{0}=0.4493 \mathrm{~m}$ for the chosen $2.0^{\circ} \times 2.0^{\circ}$ averaging domain. The roughness length for scalars is usually smaller than that for momentum (Brutsaert, 1975) and chosen to be $0.1 \cdot z_{0}$. The surface sensible and latent heat fluxes are then calculated locally by means of Monin-Obukhov similarity theory. By constructing the forcing data set as described, it is assumed to be representative for the HOPE area.

Note that the LESs are run without radiation (neither interactive nor prescribed). Radiation is neglected as the radiative cooling rates are usually 1 order of magnitude smaller than the heating rates from the surface heat flux in the mixed layer (Stull, 1988). However, through the use of nudging, the effect of radiation can be regarded as indirectly accounted for.

\subsection{Relative importance of larger-scale forcing terms}

The impact of the larger-scale forcing terms on the numerical solution is evaluated and quantified. For that purpose the budget terms of the prognostic equations for liquid water potential temperature $\theta_{1}$ and total water mixing ratio $q_{\mathrm{t}}$ of the simulation RP are compared. Figure 2 shows the tendency terms, which were horizontally and also vertically averaged. The vertical average is taken between the surface and the depth of the boundary layer $z_{i}$ (in case $z_{i}<500 \mathrm{~m}$, the upper limit for the averaging is $500 \mathrm{~m}$ to also obtain meaningful information at nighttime (robust statistics), when the boundary layer is resolved by a few grid points only).

It is apparent that during the daytime the fast physics have the largest impact on the numerical solution on most of the days. The impact of the different larger-scale forcing terms is comparably small. Sometimes (e.g., 26 April, 5 May and 11 May) the larger-scale forcing terms are also of opposite sign. A clear exception is 26 April, on which a frontal passage occurs (see Sect. 3). Here, the fast physics have almost no impact on the numerical solution, and the larger-scale forcing terms dominate the change of $\theta_{1}$ and $q_{\mathrm{t}}$ inside the boundary layer. Before noon on 26 April the LSA and SUB tendencies heat the boundary layer, and then the LSA tendencies cause a rapid and strong cooling. However, judging from the nudging tendencies for $\theta_{1}$, this cooling should begin some hours earlier. This circumstance may be caused by the low temporal resolution of the forcing data ( $3 \mathrm{~h}$ intervals). As the nudging tendencies are corrective tendencies, they are also a measure of the deviation between the states of COSMO and the LES. Since the nudging tendencies are generally smaller than the LSA and SUB tendencies, the latter are a sufficient representation of larger-scale physics. However, days with 


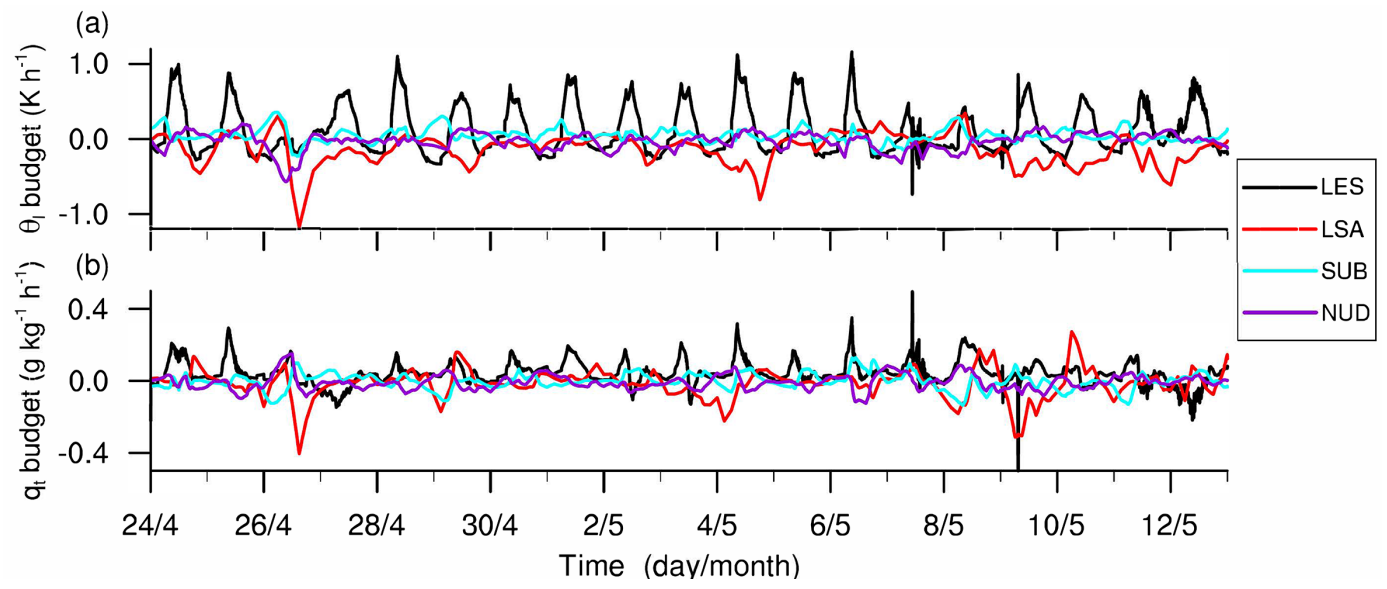

Figure 2. Temporal evolution of the vertically averaged budget terms of liquid water potential temperature (a) and total water mixing ratio (b) of case RP. The black lines (LES) show the sum of fast LES physics (advective, subgrid diffusive and microphysical) tendencies, the red lines (LSA) denote the tendencies due to larger-scale horizontal advection, the cyan lines (SUB) show the larger-scale subsidence tendencies and the violet lines (NUD) denote the nudging tendencies. The vertical average is taken between the surface and the depth of the boundary layer $z_{i}$ (in case $z_{i}<500 \mathrm{~m}$, the upper limit for the averaging is $500 \mathrm{~m}$ ).

strong larger-scale forcing usually show slightly larger nudging tendencies.

At nighttime all the tendencies are equally important. The grid spacing of $50 \mathrm{~m}$ used in the LES is much too coarse to resolve processes in the stable, nocturnal boundary layer. Thus, the larger-scale forcing terms from COSMO keep the LES in check at night. However, van Stratum and Stevens (2015) suggest that the influence of biases in the representation of the nocturnal boundary layer do not substantially influence the subsequent daytime development.

\section{HOPE}

HOPE took place near Jülich (located in the western part of Germany) in April and May 2013. The agricultural area around the permanent observational site JOYCE (Jülich Observatory for Cloud Evolution (JO) at $50.907^{\circ} \mathrm{N}, 6.414^{\circ} \mathrm{E}$, 111 m a.m.a.l.; Löhnert et al., 2015) was chosen to employ various in situ and remote sensing instruments to capture a most complete set of atmospheric parameters at a high temporal and spatial resolution. JOYCE was complemented by two additional measurement sites, LACROS (Leipzig Aerosol and Cloud Remote Observations System (LA) at $50.880^{\circ} \mathrm{N}, 6.415^{\circ} \mathrm{E}, 99 \mathrm{~m}$ a.m.s.l.; Bühl et al., 2013) and the KITcube (Karlsruhe advanced mobile observation platform (Kc) at $50.897^{\circ} \mathrm{N}, 6.464^{\circ} \mathrm{N}, 110 \mathrm{~m}$ a.m.s.l.; Kalthoff et al., 2013) during the HOPE period. The locations of the three sites and Jülich are shown in Fig. 1. Additional surface flux measurements used in this study were obtained at the Kc site Wasserwerk and the three TERENO (TERrestrial Network of Observations, TER; Zacharias et al., 2011) sites Selhausen, Ruraue and Niederzier (see Fig. 1b), where energy balance stations were located. Within a $50 \mathrm{~km} \times 50 \mathrm{~km}$ domain centered around JOYCE, the Eifel mountain range is located southwest of the HOPE domain (see Fig. 1a). The most significant orographic element in the area around the HOPE sites is the Sophienhöhe (which can be seen in the upper right part of Fig. 1b) with a maximum altitude of $301 \mathrm{~m}$ a.m.s.l. This element results from an open-pit mine located east of Sophienhöhe. The measurements during HOPE were taken by a multitude of instruments, such as Doppler lidars, Raman lidars, differential absorption lidar, ceilometers, microwave radiometers, cloud Doppler radars, meteorological towers, eddy-covariance stations and radiosondes. However, only a selection of these measurements are actually used in this study, as the main emphasis is put on boundary layer characteristics and turbulence.

The 19-day period from 24 April to 12 May 2013 was chosen for the following reasons. This period contains different weather regimes (clear-sky, convective, cloudy, frontal and post-frontal situations). Furthermore, during this time span 7 of the 18 conducted intensive observation periods (IOPs) in which the temporal coverage of measurements was higher (e.g., radiosondes were launched every $2 \mathrm{~h}$ during the daytime) took place. Moreover, it covers the passage of a frontal system, i.e., an event that is strongly controlled by fastchanging larger-scale flow conditions. The frontal passage allows the study of how the LES models react to such forcings. The selected period is too short for a feasible statistical analysis as conducted by Schalkwijk et al. (2015), but it is long enough to showcase and analyze the general capability of performing long-term LESs.

The synoptic conditions during the 19-day period can be grouped into four different periods. During the first 2 days (24-25 April) high pressure dominated the HOPE area, resulting in a calm, clear sky (24 April) and a shallow-cumulus 
(25 April) day. On 26 April the situation changed noticeably as a frontal system passed from the northwest over the HOPE domain, accompanied by an overcast, rainy situation and followed by 3 days (27-29 April) under post-frontal, overcast conditions where temperatures were significantly lower than before. The third period covering 30 April to 6 May was characterized by a calm, high-pressure period with mostly lowto mid-level convective clouds (where 3 and 4 May were even clear-sky days). The last period began on 7 May with strong convective events (local thunderstorms). The following days were determined by local troughs of low-pressure systems forming over England, resulting in a rough and predominantly wet period with westerly gusts up to $14 \mathrm{~m} \mathrm{~s}^{-1}$. In terms of clouds, this evolution is also apparent in Fig. 4a, which displays the Cloudnet target classifications (Illingworth et al., 2007) at the LACROS site.

\section{Reference simulation}

To obtain a first visual impression of the LES data sets, snapshots of 4 different days (one out of each of the four weather periods previously described) of the PALM reference simulation RP are compared with images from the total sky imager TSI-880 (Löhnert et al., 2015) at the JOYCE site. Additionally, horizontally averaged mean profiles of potential temperature $\theta$, mixing ratio $q_{\mathrm{v}}$ from PALM and radiosondes launched at 11:00 UTC at the KITcube site, together with simulated cloud $\left(q_{\mathrm{c}}\right)$ and rain $\left(q_{\mathrm{r}}\right)$ water mixing ratios (if present), are shown in Fig. 3. The snapshots were taken at 11:00 UTC on each day corresponding to the launch time of the radiosondes. The visualization of simulated cloud fields, which was performed with the Visualization and Analysis Platform for Ocean, Atmosphere, and Solar Researchers (VAPOR; Clyne et al., 2007), allows for a first impression about the diversity of weather conditions encountered in the simulations.

Visually comparing sky imager and volume-rendered cloud fields of the 4 days (left and middle columns of Fig. 3), it can be noted that the simulated cloud types agree qualitatively with the observed ones. The three-layer vertical structure in the boundary layer on 24 April is principally reproduced by PALM (Fig. 3c). However, the potential temperature is about $2 \mathrm{~K}$ lower than measured in the well-mixed layer and up to $1 \mathrm{~K}$ lower above. On 26 April, the day when the front passes the HOPE region, a significant number of clouds and amount of precipitation are simulated at 11:00 UTC (Fig. 3f). The temperature profile of PALM is reproduced very well. However, PALM simulates a well-mixed humidity layer below $1.5 \mathrm{~km}$, which is not seen in the sounding. Similar to 24 April, the boundary layer and lower tropospheric layer are about 1 to $2 \mathrm{~K}$ colder than observed on 5 May (Fig. 3i) and also on 10 May (Fig. 31). The vertical structure is reproduced well on both later days.

\subsection{Temporal evolution}

\subsubsection{Principal character of the simulated days}

To provide an overview, we first show how well the principal character of the day in terms of clouds and precipitation is represented in the LES over the course of the 19day period. A qualitative comparison of cloud water and cloud rain produced by the LES with the Cloudnet product (Illingworth et al., 2007) at the LACROS site complemented with the weather overview archive produced during HOPE is presented. Note that Cloudnet is a composite measurement product, which is derived from ceilometers, cloud radar, microwave radiometers and output from the COSMO model (e.g., Löhnert et al., 2015).

Figure $4 \mathrm{a}$ shows the Cloudnet target classification at LACROS. Roughly, the period consists of 2 clear-sky days (24 April and 4 May), 9 predominantly cloudy days (25, 28, 29, and 30 April and 1, 2, 3, 5, and 6 May) and 8 days where precipitation occurred (26 and 27 April and 7, 8, 9, 10, 11 , and 12 May). Applying the same qualitative criteria (clear sky, cloudy and rainy) to the PALM and UCLA-LES representation of clouds and precipitation in terms of cloud and rainwater mixing ratios (Fig. $4 \mathrm{c}$ and d), the following summary can be given (see also Table 2). On 2 days (25 April, 1 May), both LES models were not able to simulate shallow cumuli during the day, although shallow cumuli were observed. Precipitation was simulated on too few days. UCLALES did not simulate precipitation on 3 days and PALM on 1 day. This sums up to a qualitative agreement in the principal character of the day on 16 days for PALM and 14 days for UCLA-LES, which is an agreement of 84 and $74 \%$, respectively.

Comparing specific cloud and rainwater mixing ratios of the two LES models with the COSMO forcing (Fig. 4b), we want to stress that only a warm-rain microphysics scheme has been applied in both models. This clearly restricts the possibility to realistically form upper-level clouds and precipitation in the LES as these processes usually require the ice phase in midlatitudes. Nonetheless, PALM and UCLALES both find a representation of higher-level clouds, especially on days with a strong impact of larger-scale forcing like the frontal day of 26 April. The shallow cloud layers usually form on top of the boundary layer as can be seen in Fig. $4 \mathrm{c}$ and d. These cloud layers usually find a good representation when using a warm-microphysics scheme only. However, the simulation of proper shallow-cumulus layers (25 April and 1 May) is a challenge for PALM and UCLALES on some days.

The cloud and precipitation structure over the 19 days is very similar in both models, but UCLA-LES produces a lesser amount of cloud and rainwater (the latter leading to 2 more days of qualitative misrepresentation in UCLA-LES as compared to PALM; see Table 2). This difference roots in the usage of different advection schemes for scalars as 
Table 1. Overview of the HOPE measurements used in this study.

\begin{tabular}{|c|c|c|c|c|c|}
\hline Variables & Explanation & Device & Location & Time span & References \\
\hline \multirow[t]{4}{*}{$z_{i}$} & \multirow[t]{4}{*}{ Boundary layer depth } & Doppler lidar HALO & JOYCE & 24 Apr-12 May & Schween et al. (2014) \\
\hline & & Raman lidar Polly XT & LACROS & 24 Apr-12 May & Baars et al. (2008), \\
\hline & & 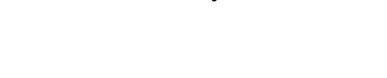 & & & $\begin{array}{l}\text { Althausen et al. (2009), } \\
\text { Engelmann et al. (2016) }\end{array}$ \\
\hline & & Radiosondes (Graw DFM-09) & KITcube & 24 Apr-12 May & Kalthoff et al. (2013) \\
\hline $\mathrm{cc}$ & Cloud cover & Total Sky Imager TSI-880 & JOYCE & $\begin{array}{l}24 \text { Apr, } 26 \text { Apr, } \\
5 \text { May, } 10 \text { May }\end{array}$ & Löhnert et al. (2015) \\
\hline $\begin{array}{l}\text { IWV, } \\
\text { LWP }\end{array}$ & $\begin{array}{l}\text { Integrated water vapor, } \\
\text { liquid water path }\end{array}$ & $\begin{array}{l}\text { Microwave radiometer } \\
\text { HATPRO }\end{array}$ & JOYCE & 24 Apr-12 May & $\begin{array}{l}\text { Löhnert et al. (2015), } \\
\text { Steinke et al. (2015) }\end{array}$ \\
\hline $\begin{array}{l}\text { shf, } \\
\text { lhf }\end{array}$ & $\begin{array}{l}\text { Surface sensible heat flux, } \\
\text { surface latent heat flux }\end{array}$ & Energy balance stations & $\begin{array}{l}\text { KITcube } \\
\text { Kc Wasserwerk } \\
\text { TER Selhausen } \\
\text { TER Niederzier } \\
\text { TER Ruraue }\end{array}$ & 24 Apr-12 May & $\begin{array}{l}\text { Kalthoff et al. (2013), } \\
\text { Maurer et al. (2016), } \\
\text { Graf et al. (2010), } \\
\text { Zacharias et al. (2011) }\end{array}$ \\
\hline$\overline{w^{\prime 2}}$ & Vertical velocity variance & $\begin{array}{l}\text { Doppler lidar WLS7-V2 } \\
(z<400 \mathrm{~m}), \text { Doppler } \\
\text { lidar WindTracer } \\
\text { WTX }(z \geq 400 \mathrm{~m})\end{array}$ & KITcube & 24 Apr, 5 May & Maurer et al. (2016) \\
\hline$\overline{T^{\prime 2}}$ & Temperature variance & Rotational Raman lidar (RRL) & KITcube & 24 Apr, 5 May & Behrendt et al. (2015) \\
\hline${\overline{\rho_{\mathrm{V}}^{\prime}}}^{2}$ & Absolute humidity variance & $\begin{array}{l}\text { Water vapor differential } \\
\text { absorption lidar (WVDIAL) }\end{array}$ & KITcube & 24 Apr, 5 May & Muppa et al. (2016) \\
\hline$z_{\mathrm{cb}}$ & Cloud-base height, & Cloudnet & JOYCE & 24 Apr-12 May & Illingworth et al. (2007) \\
\hline$z_{\mathrm{ct}}$, & cloud-top height, & Cloudnet & LACROS & & Illingworth et al. (2007) \\
\hline$d_{\mathrm{c}}$ & cloud-layer depth & Ceilometer CHM15k & JOYCE & & Löhnert et al. (2015) \\
\hline $\begin{array}{l}T_{2 \mathrm{~m}} \\
|v|_{h, 120 \mathrm{~m}} \\
\text { wdir }_{120 \mathrm{~m}}\end{array}$ & $\begin{array}{l}\text { Temperature at } 2 \mathrm{~m}, \\
\text { wind speed at } 120 \mathrm{~m}, \\
\text { wind direction at } 120 \mathrm{~m}\end{array}$ & $120 \mathrm{~m}$ meteorological tower & JOYCE & 24 Apr-12 May & Löhnert et al. (2015) \\
\hline
\end{tabular}

Most of the data sets are available via the Standardized Atmospheric Measurement Data (SAMD) archive at https://icdc.cen.uni-hamburg.de/index.php?id=samd and http://doi.org/10.17616/R3D944.

PALM uses a fifth-order scheme, whereas UCLA-LES applies a monotone second-order scheme with a flux limiter (see Sect. 2.1). Monotone schemes show a rather diffusive character (Durran, 1999). Thus, the horizontal and vertical gradients are smoothed more strongly in UCLA-LES than in PALM, which could even lead to a complete damping of small amplitudes of humidity and updrafts, prohibiting formation of weak clouds and precipitation. Furthermore, the specific rainwater is slightly better represented in the LESs than in COSMO. COSMO shows much more rain than observed.

\subsubsection{Boundary layer depth}

The boundary layer depth $z_{i}$ is one of the major defining characteristics of the boundary layer. In this study, $z_{i}$ has to be determined for different types of boundary layers (stable, convective and cloud-topped) and the respective transitional phases because several diurnal cycles are simulated. Therefore, a robust criterion that works well for the differ- ent boundary layer types, has to be chosen for an adequate determination of $z_{i}$. However, most established methods are closely tied to one boundary layer type (e.g., the height of the minimum buoyancy flux for the convective boundary layer). Thinking of a broader definition of the boundary layer, it can be identified as the layer in which turbulent mixing occurs due to the presence of the surface. The dimensionless Richardson number $R i$ is defined as the ratio of buoyancy to shear production of turbulence kinetic energy. The boundary layer depth can also be defined as the height where $R i$ exceeds a critical value as $R i$ provides a measure of the dynamic stability of the flow. Criteria based on $R i$ have been frequently used in a number of studies over the last decades (e.g., Richardson et al., 2013, and references therein). The bulk Richardson number $R i_{\mathrm{b}}$ is derived from the gradient Richardson number by approximating local gradients to a finite difference across a layer and it is defined as 

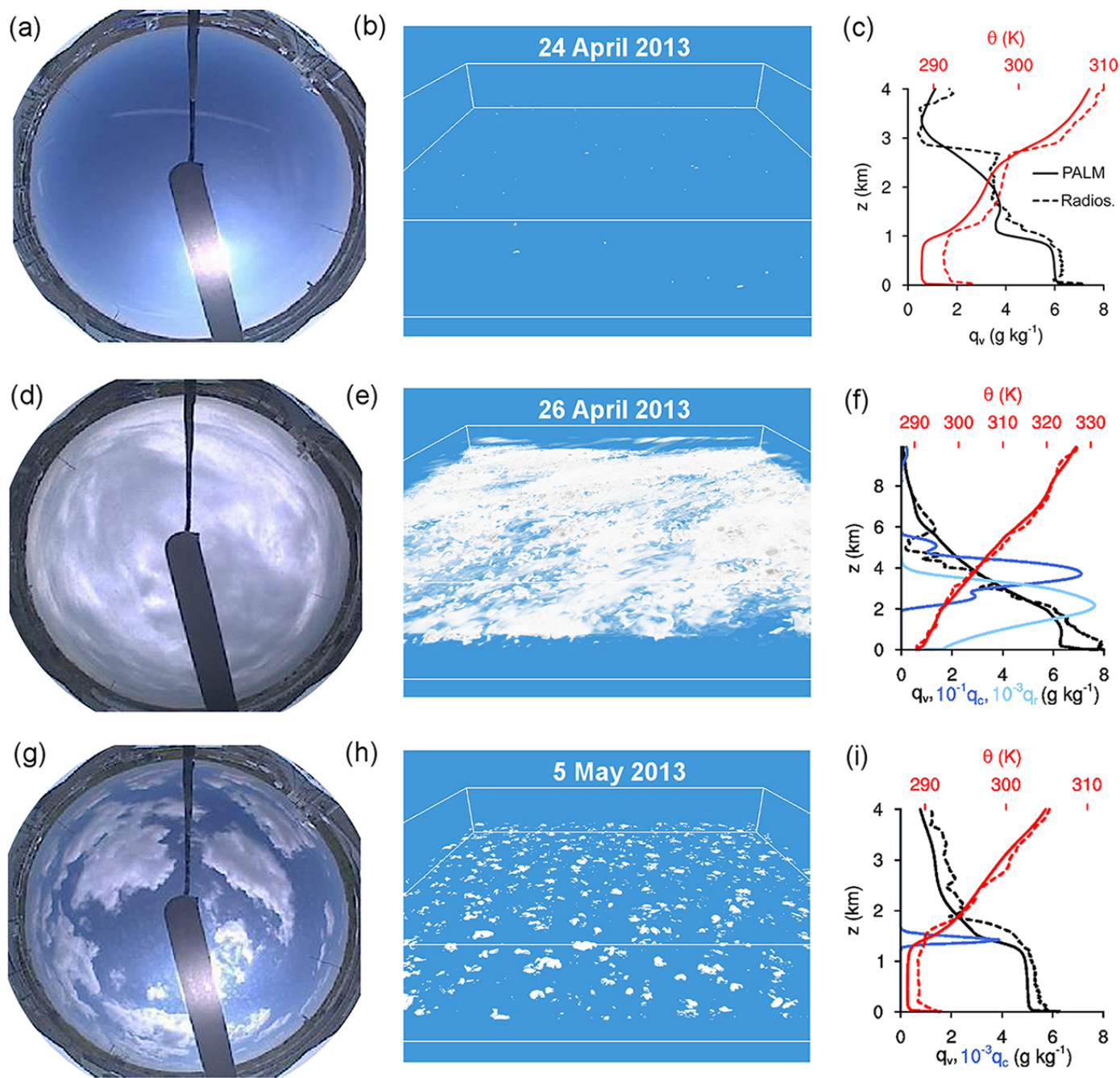

(h)
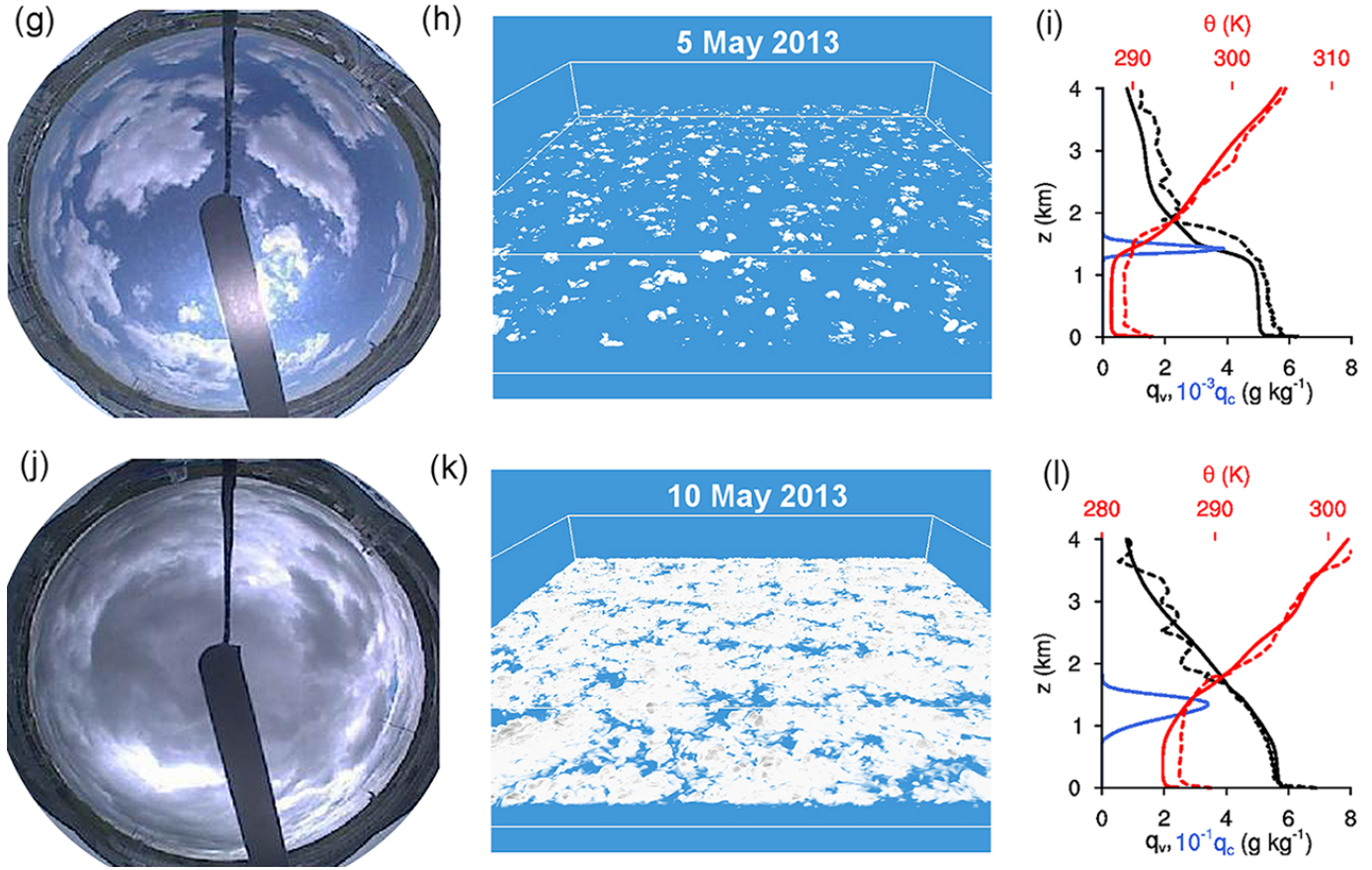

$(\mathrm{k})$
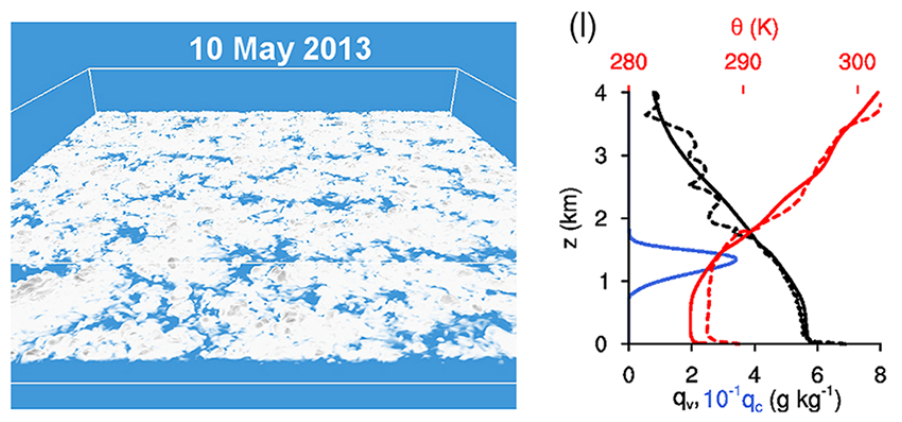

Figure 3. Snapshots and mean profiles of four different days (24 April, 26 April, 5 May and 10 May) taken at 11:00 UTC. The left column (a, d, g, j) shows images taken with the Total Sky Imager TSI-880 at the JOYCE site, the middle column (b, e, h, k) shows volume-rendered cloud water mixing ratio $q_{\mathrm{c}}$ of the PALM reference simulation RP, and the right column (c, f, i, l) shows mean profiles of mixing ratio $q_{\mathrm{v}}$ (black), potential temperature $\theta$ (red), cloud and rainwater mixing ratios $q_{\mathrm{c}}$ (blue), and $q_{\mathrm{r}}$ (light blue), respectively. The solid lines are horizontally averaged profiles of RP and the dashed lines are profiles from radio soundings (radios.) launched at the KITcube site. Note that the vertical axis in (f) extends up to $10 \mathrm{~km}$.

$R i_{\mathrm{b}}=\left(\frac{g}{\theta_{\mathrm{v}, \mathrm{s}}}\right) \frac{\theta_{\mathrm{v}}-\theta_{\mathrm{v}, \mathrm{s}}}{u_{1}^{2}+u_{2}^{2}} \cdot z$

where $g$ is the acceleration due to gravity, $\theta_{\mathrm{v}}$ denotes the virtual potential temperature and $\theta_{\mathrm{v}, \mathrm{s}}$ is its value close to the surface. Following classical theory (Taylor, 1931), turbulence 
Table 2. Summary on qualitative agreement in the principal character of the simulated days compared to Cloudnet and the HOPE weather overview archive.

\begin{tabular}{|c|c|c|c|c|}
\hline \multirow[t]{2}{*}{ Criteria } & \multicolumn{2}{|c|}{ PALM } & \multicolumn{2}{|l|}{ UCLA-LES } \\
\hline & Days & No. days & Days & No. days \\
\hline LES days without shallow cumuli, when shallow cumuli were observed & 25 Apr, 1 May & 2 & 25 Apr, 1 May & 2 \\
\hline LES days without rain, when rain was observed & 8 May & 1 & 26 Apr, 8 May, 9 May & 3 \\
\hline LES days with qualitative agreement to observations & Remaining & 16 & Remaining & 14 \\
\hline
\end{tabular}
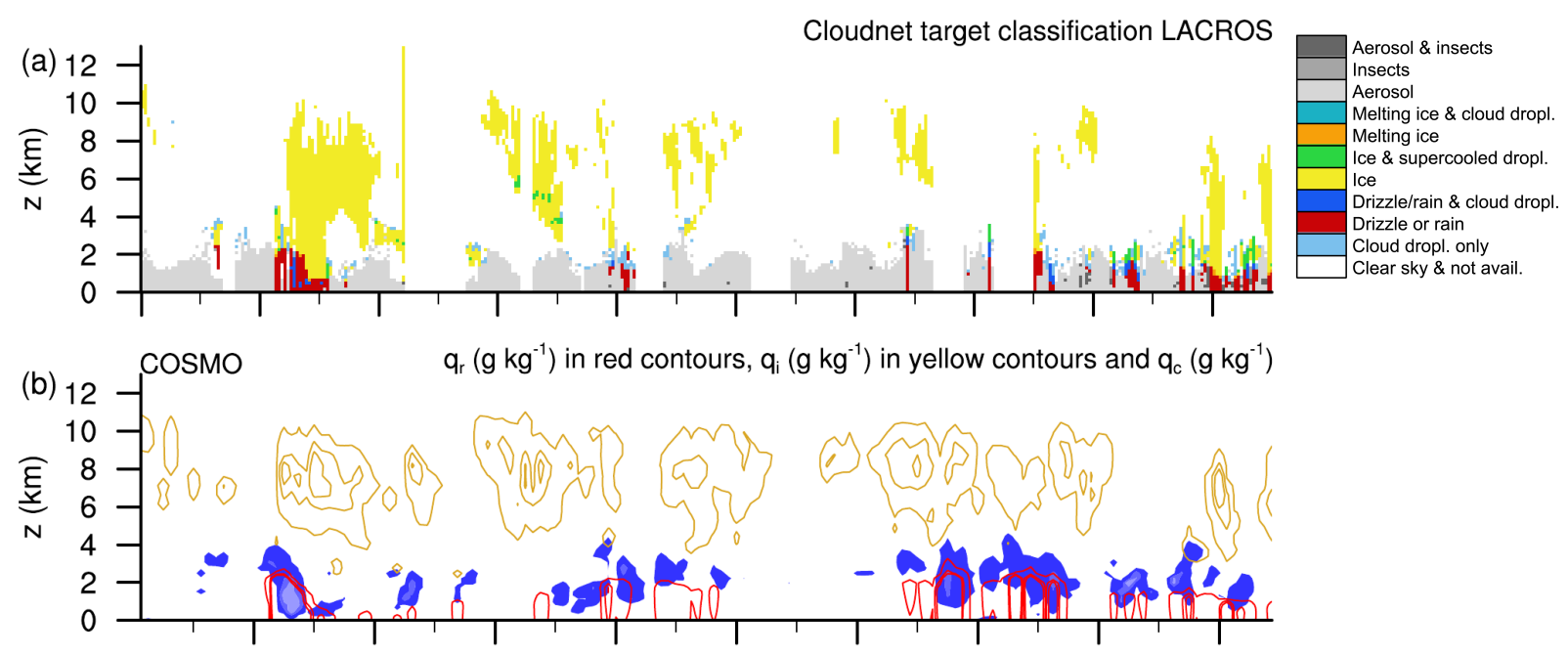
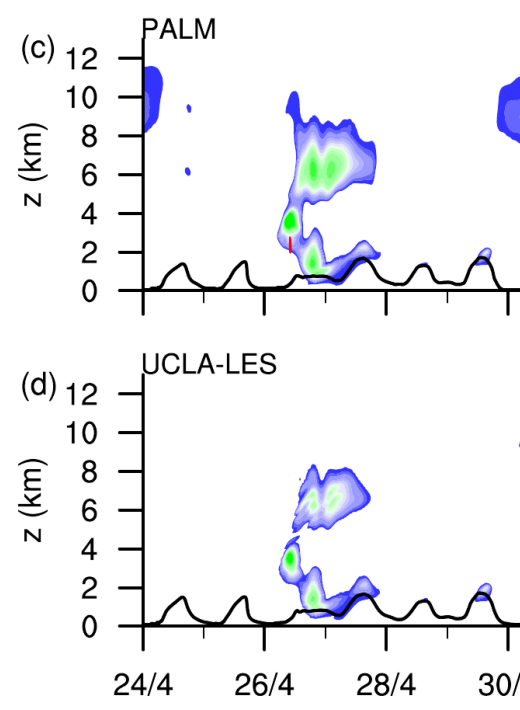

$\mathrm{q}_{\mathrm{r}}\left(\mathrm{g} \mathrm{kg}^{-1}\right)$ in red contours and $\mathrm{q}_{\mathrm{c}}\left(\mathrm{g} \mathrm{kg}^{-1}\right)$

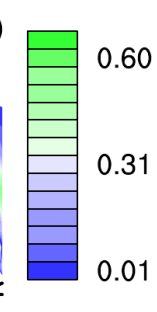

Figure 4. Time-height cross sections of Cloudnet target classification in (a), specific cloud ice $q_{\mathrm{i}}$ (in yellow contours ranging from 0.001

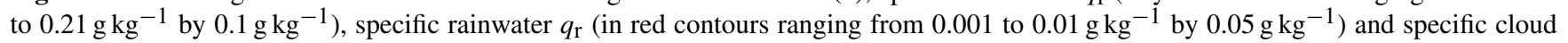
water $q_{\mathrm{c}}$ (colored contours) of the COSMO forcing in (b), specific cloud and rainwater of PALM (run RP) in (c), and specific cloud and rainwater of UCLA-LES (run RU) in (d). The red contours in (c) and (d) have the same values as in (b). The black lines in (c) and (d) denote the boundary layer depth according to the bulk Richardson number criterion (see also Fig. 5). The same color bar is used in (b)-(d). Note that in (b)-(d) the time series of horizontally averaged profiles are shown.

of a homogeneous stably stratified sheared flow in steady state decays, if the gradient Richardson number exceeds a value of 0.25 . In the definition (Eq. 5), $R i_{\mathrm{b}}$ is defined from the surface upwards. If $z$ is replaced by the boundary layer depth $z_{i}, R i_{\mathrm{b}}$ becomes the critical bulk Richardson number whose value depends on stability (e.g., Richardson et al., 
2013; Basu et al., 2014). However, this dependence is neglected in this study and a value of $R i_{\mathrm{b}, \mathrm{c}}=0.25$ is assumed to be valid for all stability regimes. This applied value also lies in the interval for the critical bulk Richardson number $0.2<R i_{\mathrm{b}, \mathrm{c}}<0.5$, proposed by Zilitinkevich and Baklanov (2002).

In PALM and UCLA-LES, $z_{i}$ is determined locally (at each grid point in the horizontal domain). Starting at the lowest prognostic level and continuing upwards, $R i_{\mathrm{b}}$ is calculated using Eq. (5) until $R i_{\mathrm{b}}>R i_{\mathrm{b}, \mathrm{c}}=0.25$. The height of the grid point at which the critical value is exceeded is then assumed to coincide with $z_{i}$. For $\theta_{\mathrm{v}, \mathrm{s}}$ the second prognostic level above the surface is used. The resulting 2-D field of $z_{i}$ is then averaged horizontally and the horizontal variability is quantified by means of retaining the standard deviation.

Figure 5 shows the temporal evolution of the boundary layer depth. The aforementioned spatial variability is depicted as twice the standard deviation in light gray shading for PALM and light green shading for UCLA-LES in Fig. 5. It is strongest during the daytime. The bulk Richardson number criterion is also applied to the mean COSMO profiles and the resulting $z_{i}$ is shown as a blue dashed line. The LES models produce a very similar boundary layer depth. Both models lag behind COSMO. As the LESs are tied to the COSMO forcing, they also show peak heights close to COSMO. This behavior can partly be attributed to the Newtonian relaxation, which pulls the LES back towards the mean state given by the forcing.

Measurements from the three different major HOPE sites are taken into account for evaluating the performance of the LES models in terms of the boundary layer depth. The aerosol Raman lidar Polly XT (Althausen et al., 2009, Polly hereafter) at the LACROS site provides an estimate for the boundary layer depth based on the heights where the detected aerosols show a strong backscatter signal (Baars et al., 2008). The Doppler wind lidar HALO provides profiles of vertical velocity variance at the JOYCE site from which the boundary layer depth is deduced as the lowest height from the surface onwards where the vertical velocity variance is smaller than a threshold of $0.4 \mathrm{~m}^{2} \mathrm{~s}^{-2}$ (Schween et al., 2014). As a third data source 78 radio soundings from the KITcube site were used. The bulk Richardson number method was applied to the available soundings. In analyzing the soundings erroneous values near the surface were detected; thus, the critical $R i_{\mathrm{b}}$ is calculated from $100 \mathrm{~m}$ onwards. The criteria applied to the lidar data (vertical velocity variance and aerosol layer) are not boundary layer regime independent and usually work best for convective boundary layer situations. However, they are a standard measurement product and the independent measurements of $z_{i}$ used in this study provide a general corridor for a representative boundary layer depth observed in the HOPE domain. Due to the different methods used to deduce the boundary layer depth, the aerosol lidar typically shows larger depths than the wind lidar (see Fig. 5) as the detected aerosol layers are a passive tracer for the boundary layer depth as compared to the dynamic criterion based on vertical velocity variance.

On most days, PALM, UCLA-LES and COSMO are able to reproduce the development of the boundary layer as the models lie inside the spread of the measurements resulting from surface heterogeneity and spatial variability of the boundary layer depth between the three sites. On days with strong vertical forcing, which are stippled in Fig. 5, the simulated peak depths agree less well with the observations. A day is characterized as a day with strong vertical forcing in case the prescribed larger-scale subsidence velocity averaged between 4 and $8 \mathrm{~km}$, denoted as $\widetilde{w_{\mathrm{SUB}}}$ in the following, is larger than $5 \mathrm{~cm} \mathrm{~s}^{-1}$.

On 25 April, a day when shallow cumulus was observed but not simulated (see Table 2), the peak height is strongly underestimated by the LES, but also by the host model COSMO. Overall, the daily development of the boundary layer depth can be qualitatively reproduced by both LES models.

\subsubsection{Further boundary layer quantities}

Figures 6-8 give a further overview about the performance of the LES for boundary layer quantities like the surface sensible and latent heat fluxes, near surface wind direction, wind speed and potential temperature, and the integrated water vapor (IWV) and liquid water path (LWP). For the LES, the horizontal mean of the quantities is shown. At first glance, general agreement with observations is given. PALM and UCLA-LES are nearly indistinguishable apart from LWP. They are also rather close to COSMO.

In the reference setup, potential temperature and humidity from the COSMO averaging box are prescribed homogeneously at the surface and the sensible and latent heat fluxes (shf and lhf) are calculated locally via Monin-Obukhov similarity theory (see Sect. 2.3). These surface fluxes are very important as they directly determine the amount of energy input into the boundary layer. In Fig. 6 the surface fluxes from PALM and UCLA-LES are compared with the fluxes from the COSMO forcing and measurements from different energy balance stations. A total of five different stations located over different land-use classes in close vicinity to the principal HOPE sites are taken into account (see Fig. 1b). From these measurements spatially representative values of the surface fluxes are derived and provided by Maurer et al. (2016). A weighted average (w.av.) of the five stations with the fraction of the respective land-use class in an area of $30 \mathrm{~km} \times 30 \mathrm{~km}$ centered around the KITcube site is calculated (see Maurer et al., 2016, for further details). The weighted average is marked by purple stars in Fig. 6. The fluxes at the individual stations show a considerable spread reflecting the large spatial variability for surface fluxes (heterogeneity) in the HOPE region. By construction, shf and $\mathrm{lhf}$ in the LES are closely tied to the surfaces fluxes in the forcing and also slightly lag behind like the boundary layer depth. 

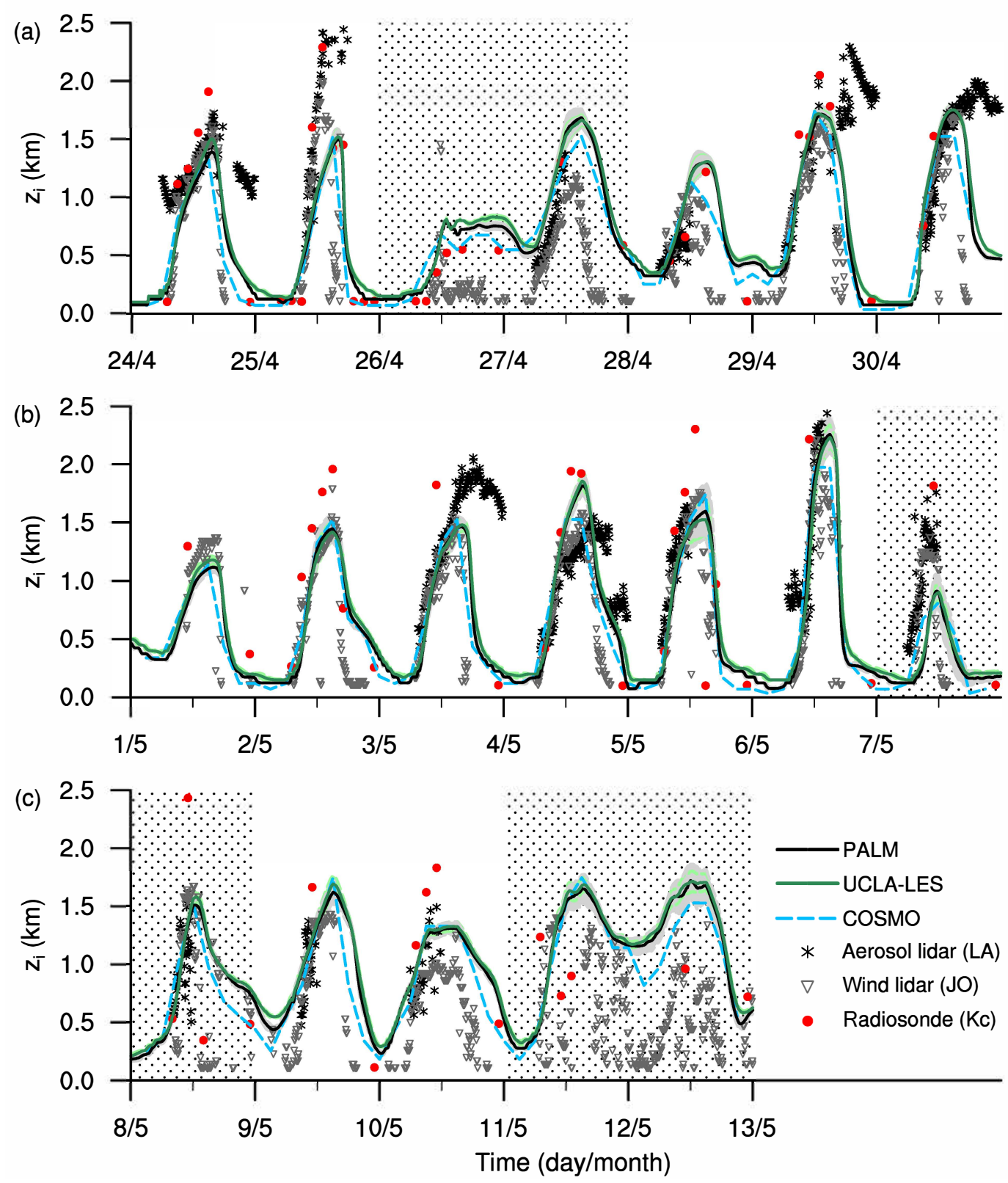

Figure 5. Temporal evolution of the boundary layer depth $z_{i}$ for the total 19-day period (grouped in weeks). $z_{i}$ is determined by means of the bulk Richardson number criterion in all three models (PALM, UCLA-LES and COSMO) and in the radiosonde data. A criterion based on the vertical velocity variance and detected aerosol layers is used for the wind lidar and aerosol lidar, respectively. Radiosondes were launched at the KITcube site; the wind lidar and aerosol lidar took measurements at the JOYCE and LACROS sites, respectively. Gray and green shading denote twice the standard deviation of $z_{i}$ in PALM and UCLA-LES, respectively. Stippled highlighting marks days with strong vertical forcing $\left(\widetilde{w_{\text {SUB }}}>0.05 \mathrm{~m} \mathrm{~s}^{-1}\right)$.

They roughly agree with the weighted average on most days. The peak shf in the LES and COSMO tends to be overestimated compared to the weighted average, whereas the $\mathrm{lhf}$ tends to be underestimated, especially for the last 6 days of the simulation period. Overall, the simulated surface fluxes can be seen as representative for the HOPE region.
For wind-engineering purposes, surface layer winds are very important. Measurements from the $120 \mathrm{~m}$ meteorological tower at the JOYCE site (Löhnert et al., 2015) and radio soundings are compared to the LES and COSMO in Fig. 7a and $\mathrm{b}$. The wind components $u$ and $v$ were linearly interpolated between the second and third prognostic levels to obtain values for $120 \mathrm{~m}$. All major changes in wind direction at a 

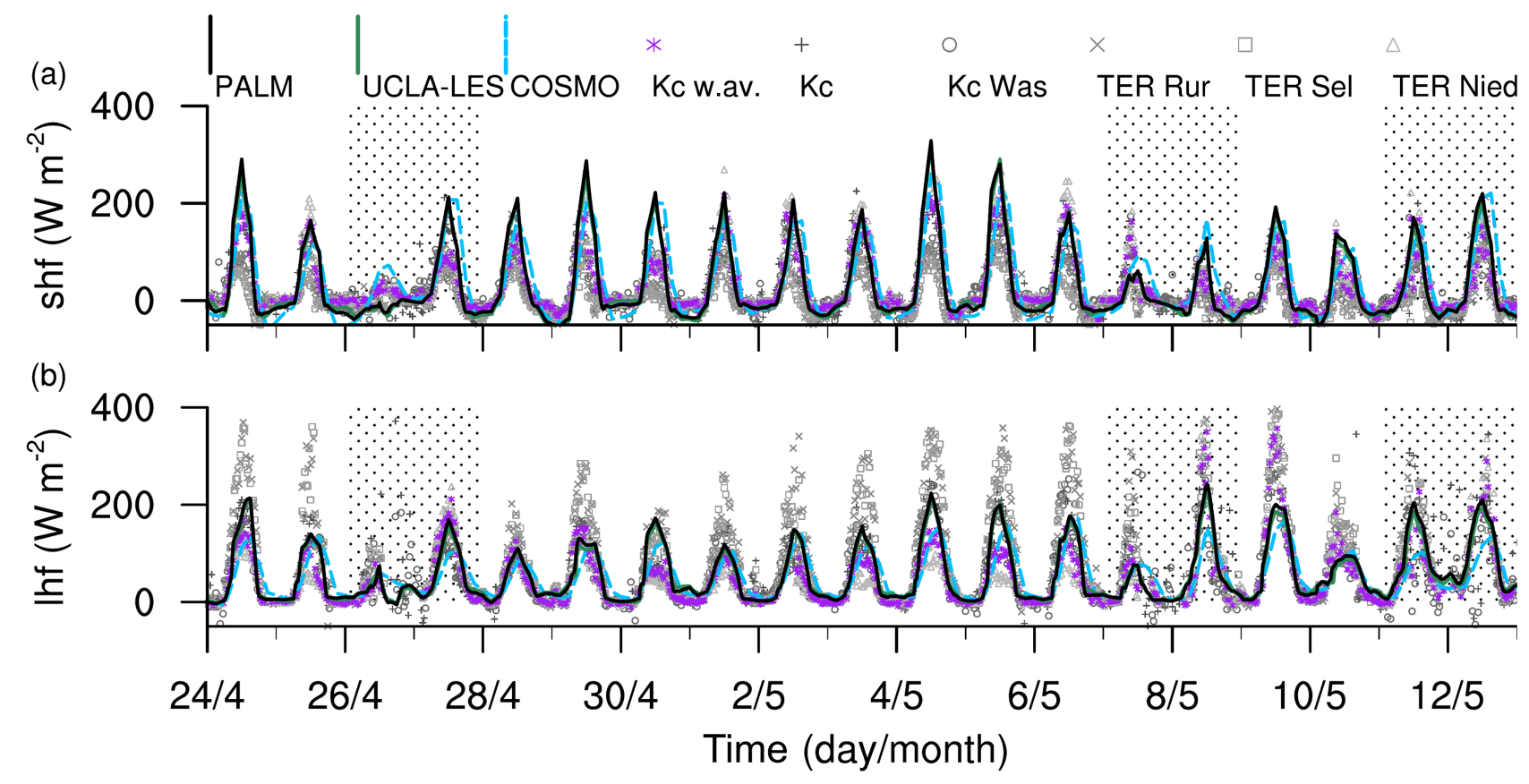

Figure 6. Temporal evolution of surface sensible heat flux shf in (a) and surface latent heat flux lhf in (b). An overview of the measurements and abbreviations is given in Table 1. Stippled highlighting marks days with strong vertical forcing $\left(w_{\mathrm{SUB}}>0.05 \mathrm{~m} \mathrm{~s}^{-1}\right)$.

height of $120 \mathrm{~m}$ can be reproduced very well by the two LES models and COSMO (Fig. 7a). For the wind speed at $120 \mathrm{~m}$ height, the tower measurements and soundings show larger fluctuations than the models as the point measurements contain turbulent signals that are smoothed out in the horizontal mean of the LES output that is shown. Taking these differences into account, the LESs agree rather well with the wind speed observations.

The near-surface potential temperature at a height of $25 \mathrm{~m}$ from the JOYCE tower, the radio soundings and the LES is depicted in Fig. 7c. For the LES the output at the first prognostic level is taken. PALM, UCLA-LES and COSMO are systematically too warm at night. During the daytime, the LESs are usually colder (with some exceptions on 26 April, 27 April and 11 May). Overall, there is good agreement with observations, although the amplitudes of the observations are slightly larger.

Observations of the column-integrated quantities, IWV and LWP, shown in Fig. 8, are provided by the microwave radiometer HATPRO (Löhnert et al., 2015; Steinke et al., 2015) at the JOYCE site. There is good agreement for IWV between the LES, COSMO and HATPRO. Hence, the total amount of water vapor is accurately included in the LES by means of the larger-scale forcing method. The LWP (Fig. 8b) of the LES matches the observations better than COSMO despite the deficiency in terms of the warm microphysics that were used. However, correctly modeling LWP (which can be seen as a proxy for clouds) with the long-term LES approach is rather challenging.
The 6 days with strong vertical forcing (stippled) all show rather high values of LWP in rough accordance with HATPRO. As already discussed in Sect. 4.1.1, there are 25 April and 1 May, when shallow clouds could not be simulated, although they had been observed, which is also apparent in Fig. 8b. Furthermore, both LESs differ more strongly compared to the previously discussed quantities as microphysics and numerics are closely tied and they are very important for allowing cloud formation in the LES.

\subsection{Vertical structure}

The main strength of LESs is to resolve turbulence. To assess whether the long-term LES approach is able to produce realistic turbulence statistics, variance profiles for two distinct situations are discussed. The variances of vertical velocity $\overline{w^{\prime}}$, potential temperature $\overline{\theta^{\prime 2}}$ and mixing ratio $\overline{q_{\mathrm{v}}^{\prime}}$ from PALM and UCLA-LES are compared to variance profiles from lidars located at the KITcube site for a $1 \mathrm{~h}$ period (11:00-12:00 UTC) for the clear-sky situation of 24 April and the shallow-cumulus situation of 5 May. Three different lidars, namely the Doppler lidar WindTracer WTX combined with the Doppler lidar WLS7 (Maurer et al., 2016) from KIT, the rotational Raman lidar (RRL; Hammann et al. (2015); Behrendt et al. (2015)) and the water vapor differential absorption lidar (WVDIAL; Muppa et al. (2016)) from the University of Hohenheim were operated simultaneously during IOPs of HOPE, allow us to compare different lidar- 


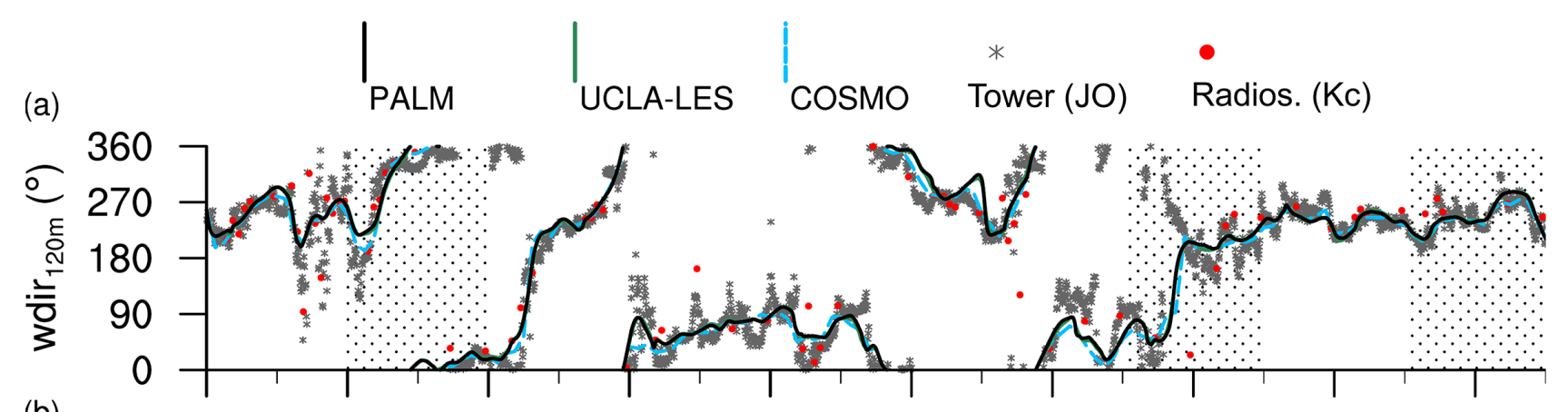

(b)

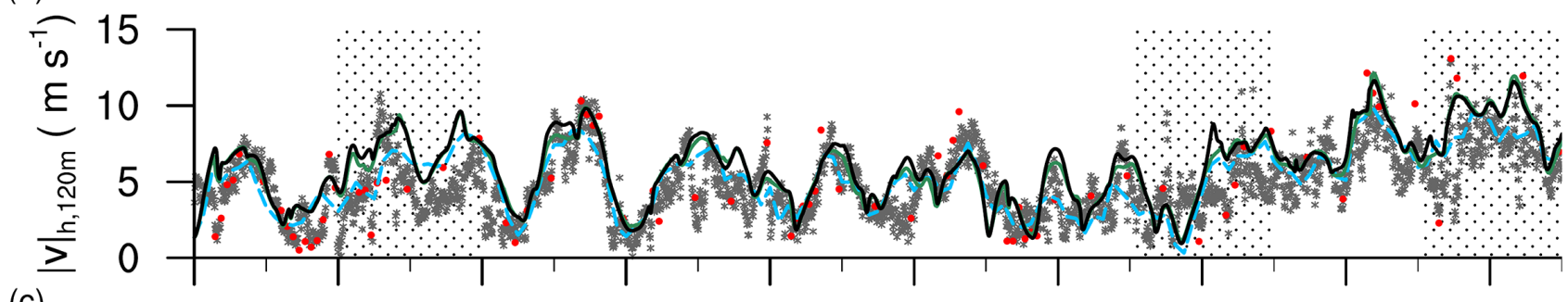

(c)

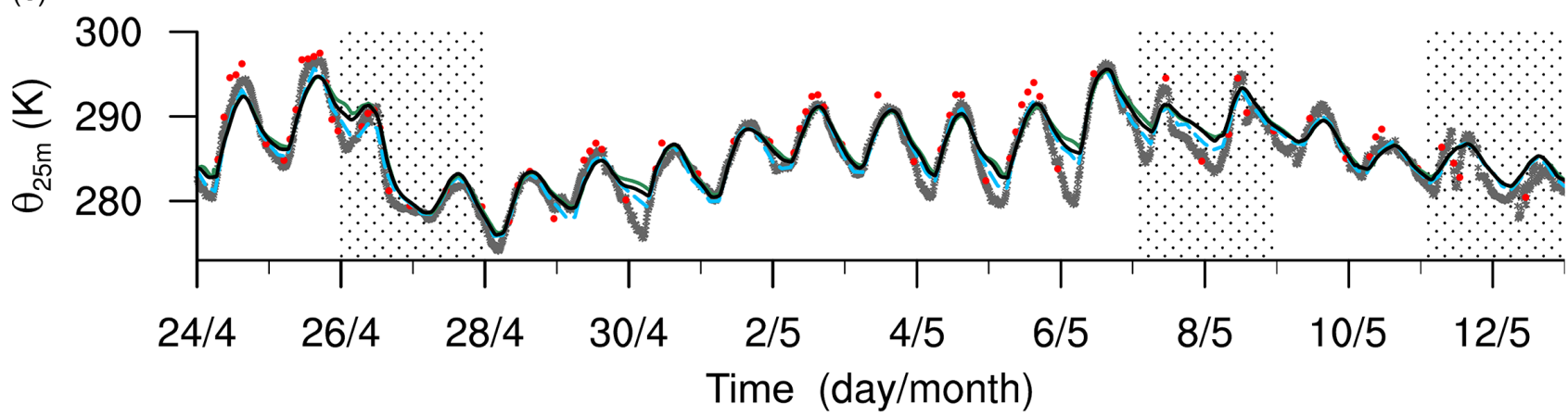

Figure 7. Temporal evolution of wind direction at $120 \mathrm{~m}$ height $\operatorname{wdir}_{120 \mathrm{~m}}$ in (a), wind speed at $120 \mathrm{~m}$ height $|\mathrm{v}|_{\mathrm{h}, 120 \mathrm{~m}}$ in (b) and potential temperature at $25 \mathrm{~m}$ height $\theta_{25} \mathrm{~m}$ in (c). An overview of the measurements and abbreviations is given in Table 1. Stippled highlighting as in Fig. 6 .

based higher-order moments with the LES to discuss the turbulence structure of the boundary layer on these 2 days.

Figure 9 shows the vertical velocity, potential temperature and mixing ratio variances for 24 April and 5 May (11:00-12:00 UTC). For 24 April, the lidar-based variances (solid purple lines) of the vertical velocity, the actual temperature and the absolute humidity were each recently published by Maurer et al. (2016), Behrendt et al. (2015) and Muppa et al. (2016). They also provide data for the cumulustopped boundary layer of 5 May; these are analyzed for the first time in the present paper. The lidar turbulence signal at each height is calculated by subtracting the linear fit of the recorded time series between 11:00 and 12:00 UTC from the original time series. Based on this turbulence time series, the variance for each record is calculated (see, e.g., Behrendt et al., 2015). Note that the actual temperature variance as given by RRL was converted to potential temperature variance assuming a constant Exner function, which was taken from the radio-sounding profile at 11:00 UTC of the respective day. The absolute humidity variance was converted similarly by means of the air density taken from the same sounding. In the cumulus case (5 May), the data points inside cloudy regions are not taken into account for the estimation of higher-order moments with RRL and WVDIAL. Furthermore, the potential temperature variance of RRL is only shown up to a height of $0.7 z_{i}$, which is near cloud base (see Fig. 9e) as the cloud layer is affected by saturation of the detector. In this case more noise is found in the data and overlaps the true data thoroughly, making the measurements less reliable.

Typically, higher-order moments from LES are deduced from a spatial (horizontal) average (e.g., Heinze et al., 2015) as opposed to lidar measurements, which define turbulence as departure from a temporal mean. To account for this difference, variances from LES are shown in two different ways in Fig. 9. The solid black and green lines denote the $1 \mathrm{~h}$ average of the variances as defined by the departure from the horizontal mean (hom). Solid gray and light green areas show 


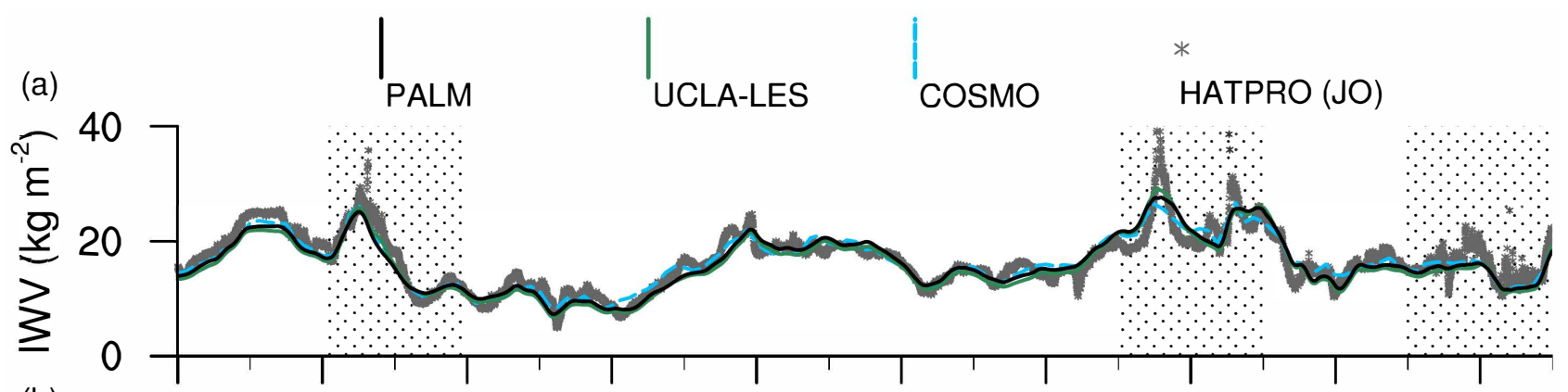

(b)

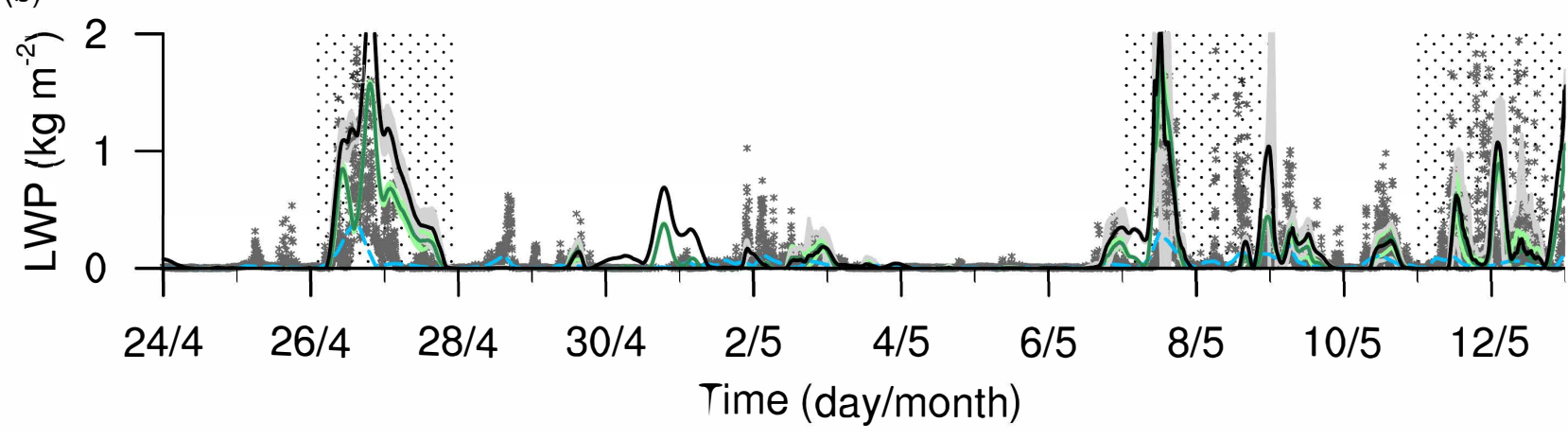

Figure 8. Temporal evolution of integrated water vapor (IWV) in (a) and liquid water path (LWP) in (b). An overview of the measurements and abbreviations is given in Table 1. Gray and green shading in (b) denote twice the standard deviation of LWP in PALM and UCLA-LES, respectively. Stippled highlighting as in Fig. 6.

twice the standard deviation, resulting from the $1 \mathrm{~h}$ average of the slab-averaged variance profiles. Furthermore, virtual measurements were conducted in the LES at four distinct locations, which are equally spaced in the modeling domain. Grid-point data for four independent columns $(\operatorname{col} X)$ with a high temporal resolution (30 $\mathrm{s}$ and $5 \mathrm{~min}$ for PALM and UCLA-LES, respectively) have been saved. These time series were used to calculate variances exactly as for the lidar data (detrending and temporal average over $1 \mathrm{~h}$ ). These variance profiles are representative for a single measurement inside the LES and are thus directly comparable to the variances deduced from lidar. They are depicted as thin dashed black and green lines in Fig. 9.

To account for a better comparison between observed and simulated variances, all profiles in Fig. 9 are scaled (nondimensionalized) by means of the free convective Deardorff (1970a) scales. These are the convective velocity scale $w^{*}=\left(\frac{g}{\theta_{v, s}} \overline{w^{\prime} \theta_{\mathrm{vs}}^{\prime}} z_{i}\right)^{\frac{1}{3}}$, the convective temperature scale $\theta^{*}=\frac{\overline{w^{\prime} \theta_{v s}^{\prime}}}{w^{*}}$ and the convective humidity scale $q^{*}=\frac{\overline{w^{\prime} q_{v s}^{\prime}}}{w^{*}}$, where $\overline{w^{\prime} \theta_{\mathrm{vs}}^{\prime}}$ denotes the kinematic surface buoyancy flux and $\overline{w^{\prime} q_{\mathrm{vs}}^{\prime}}$ is the kinematic surface latent heat flux (see Table 3). The vertical axis (height) is normalized by means of the boundary layer depth. For all lidar-derived profiles, the boundary layer depth is determined by estimating the top of the aerosol layer from lidar backscatter data (method 2 in Maurer et al., 2016). The required surface fluxes are taken from the weighted average of five different energy balance stations (see also Sect. 4.1), which is, based on Maurer et al. (2016), representative for a larger area. The LES-based scaling values are derived from the $z_{i}$ based on the bulk Richardson number and the $1 \mathrm{~h}$ average of the horizontal-mean surface buoyancy and latent heat flux. All values are summarized in Table 3.

Generally comparing the horizontal mean variances in PALM and UCLA-LES in Fig. 9, we note that they both show a very similar vertical structure. In all six cases, variances from PALM are slightly larger than variances from UCLA-LES, which becomes most prominent for the peak values of the scalar variances at the top of the boundary layer (Fig. 9b, c, e and f). The differences in variances between PALM and UCLA-LES are of the same order as discussed in several LES intercomparison studies (e.g., Stevens et al., 2001; Siebesma et al., 2003; Stevens et al., 2005). It can be attributed to different numerics like the advection scheme. As UCLA-LES uses a monotone scheme for the scalars and PALM does not (see also Sect. 2.1), fluctuations are damped more strongly, resulting in slightly less variance (turbulence).

On 24 April around noon, the boundary layer is cloudfree, well-mixed and topped by a capping inversion as seen by radio-sounding profiles in Fig. 3c. The LESs reproduce this structure, which also manifests in the variance profiles (Fig. 9a-c). The LES-based vertical velocity variances reveal the typical peak around $0.3 z_{i}$ and decrease monotonically 

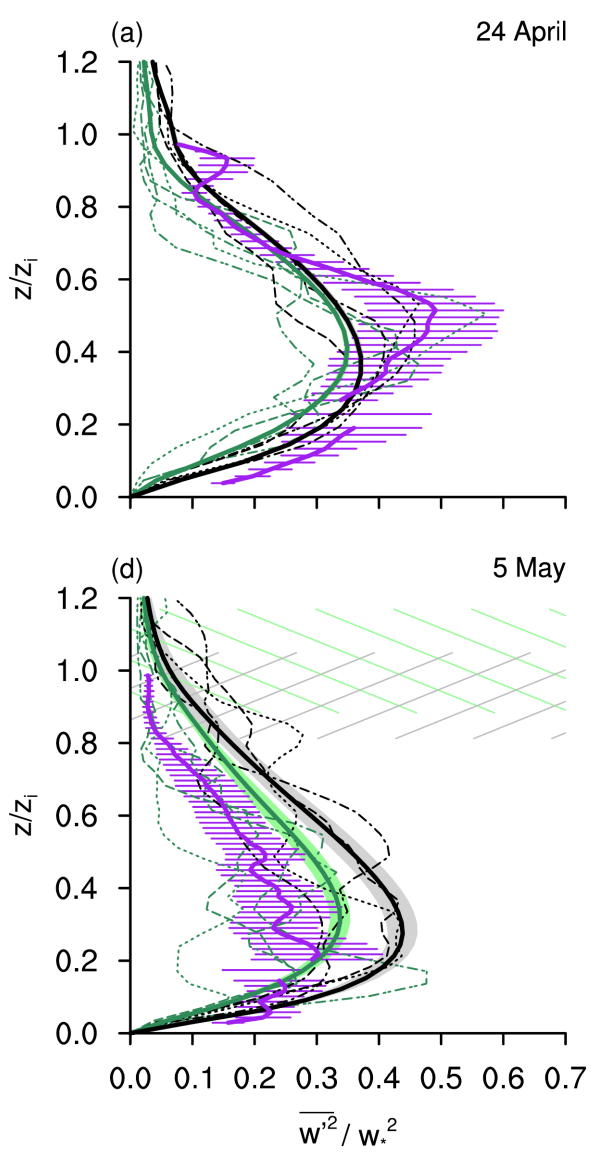

(b)

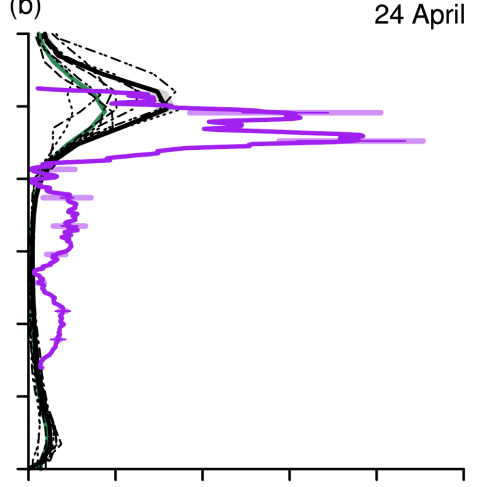

(e)

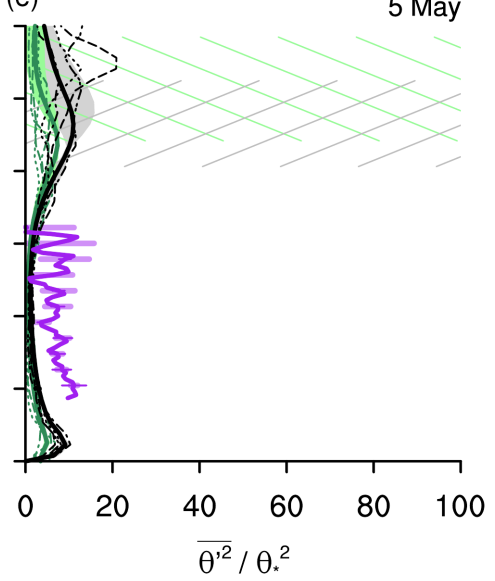

(c)
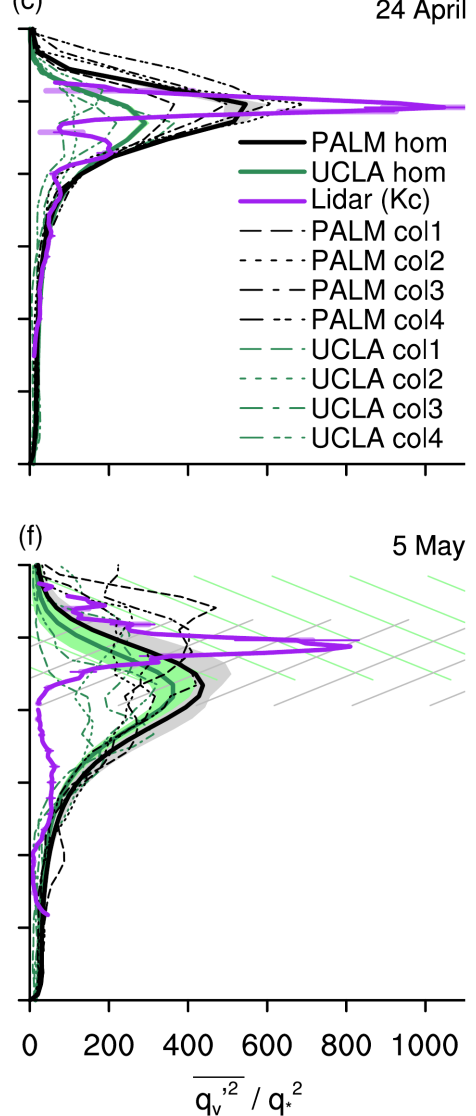

Figure 9. Normalized vertical profiles of vertical velocity variance (a, d), potential temperature variance (b, e) and mixing ratio variance (c, $\mathbf{f})$ for a $1 \mathrm{~h}$ period between 11:00 and 12:00 UTC for 24 April and 5 May 2013, respectively. Solid black and green lines show variances in PALM and UCLA-LES determined as departure from the horizontal mean (hom) and averaged over $1 \mathrm{~h}$, including standard deviations denoted as solid gray and light green areas. Thin dashed black and green lines show variances from single-column output (colX) at four different grid points determined as departure from a $1 \mathrm{~h}$ temporal mean. Solid purple lines denote variances from the KIT Doppler lidar, including the statistical error according to Lenschow et al. (1994) as error bars (a, d), the rotational Raman lidar (b, e) and the water vapor differential absorption lidar from the University of Hohenheim (c, f), (see Table 1 for further details). The thin purple (thick light purple) error bars in (b), (c), (e) and (f) show the noise (sampling) error according to Lenschow et al. (2000). Gray and light green shaded regions in (d)-(f) denote the cloud boundaries of PALM and UCLA-LES, respectively. See Table 3 for the scaling values used.

above $0.3 z_{i}$. The vertical velocity variance from Doppler lidar exhibits a maximum at around $0.5 z_{i}$ and shows a second smaller peak around $0.9 z_{i}$. A longer averaging period of about $3 \mathrm{~h}$ would lead to a decrease in the height of the lower maximum to about $0.3 z_{i}$ (Maurer et al., 2016), which emphasizes that the chosen averaging time might be too small to receive robust ${\overline{w^{\prime}}}^{2}$ statistics comparable to LES. This is confirmed by the large differences between the given virtual measurements. The horizontal mean profiles and, to a larger extent, also the virtual measurements are inside the uncertainty range of the Doppler lidar. Nonetheless, it should be kept in mind that a departure of the horizontally averaged LES variances from the lidar variances does not necessarily mean that the LES variances are not representative as the statistical error based on Lenschow et al. (1994) does not always show how large the uncertainties really are - especially in the case of heterogeneous surfaces (Sühring and Raasch, 2013).

The LES-based scalar variances show their distinct maxima on 24 April at the top of the boundary layer (Fig. 9b and c), where warmer and less-humid tropospheric air is entrained, producing large turbulent fluctuations. This is principally in accordance with the lidar measurements. The peak values of the lidar-based scalar variances are significantly higher than the ones of the LES - even when taking the virtual measurements in the LES models into account. Here, it becomes apparent that the vertical grid spacing of $50 \mathrm{~m}$ used in LES is much too coarse to sufficiently resolve the strong vertical gradients at the boundary layer top. Recently, it was demonstrated that entrainment processes have an important influence on the structure of variance profiles and should be accounted for (Wulfmeyer et al., 2016). Another reason for 
Table 3. Scaling values for 24 April 2013 and 5 May 2013 for 11:00-12:00 UTC (used in Fig. 9).

\begin{tabular}{llccc}
\hline & & PALM & UCLA-LES & Lidar $(\mathrm{Kc})$ \\
\hline 24 April 2013 & $\frac{z_{i}(\mathrm{~m})}{w^{\prime} \theta_{\mathrm{vs}}^{\prime}}\left(\mathrm{W} \mathrm{m}^{-2}\right)$ & 285.3 & 292.1 & 163.1 \\
11:00-12:00 UTC & $w^{\prime} q_{\mathrm{vs}}^{\prime}\left(\mathrm{W} \mathrm{m}^{-2}\right)$ & 168.3 & 156.0 & 129.6 \\
& $w^{*}\left(\mathrm{~m} \mathrm{~s}^{-1}\right)$ & 2.022 & 2.075 & 1.810 \\
& $\theta^{*}(\mathrm{~K})$ & 0.117 & 0.117 & 0.075 \\
& $q^{*}\left(\mathrm{~g} \mathrm{~kg}^{-1}\right)$ & 0.028 & 0.025 & 0.060 \\
\hline 5 May 2013 & $z_{i}(\mathrm{~m})$ & 1641 & 1465 & 1723 \\
11:00-12:00 UTC & $w^{\prime} \theta_{\mathrm{vs}}^{\prime}\left(\mathrm{W} \mathrm{m}^{-2}\right)$ & 181.3 & 202.1 & 185.2 \\
\cline { 2 - 5 } & $w^{\prime} q_{\mathrm{vs}}^{\prime}\left(\mathrm{W} \mathrm{m}^{-2}\right)$ & 160.9 & 140.6 & 127.5 \\
& $w^{*}\left(\mathrm{~m} \mathrm{~s}^{-1}\right)$ & 2.037 & 2.031 & 2.053 \\
& $\theta^{*}(\mathrm{~K})$ & 0.076 & 0.084 & 0.077 \\
& $q^{*}\left(\mathrm{~g} \mathrm{~kg}^{-1}\right)$ & 0.027 & 0.023 & 0.052 \\
\hline
\end{tabular}

Values are averaged over $1 \mathrm{~h}(11: 00-12: 00 \mathrm{UTC})$ on both days. Boundary layer depth $z_{i}$ in the LES is determined based on the bulk Richardson number criterion. For the lidar, $z_{i}$ is the top of the aerosol layer based on backscatter signal. Surface buoyancy and latent heat fluxes, $\overline{w^{\prime} \theta_{\mathrm{vs}}^{\prime}}$ and $\overline{w^{\prime} q_{\mathrm{vs}}^{\prime}}$, respectively, are horizontally averaged values in the LES and weighted, averaged values from the energy balance stations in the case of lidar.

the underestimation of scalar variance peak values might also be the usage of homogeneous surface forcing, which allows only the prescription of surface forcing that is representative for the larger area which might not necessarily be similar to the forcing actually present at the measurement site. The mixing ratio variance from WVDIAL shows a rather unusual lower peak at around $0.85 z_{i}$ (Fig. 9c), which Muppa et al. (2016) associate with entrainment of an elevated humidity layer into the convective boundary layer. The second peak in vertical velocity variance at around $0.9 z_{i}$ might also be associated with this event.

On 5 May a shallow-cumulus layer was observed at the JOYCE site and simulated around noon (see Fig. $3 \mathrm{~g}$ and $\mathrm{h}$ ). The mean profiles of potential temperature and mixing ratio of PALM and the radio soundings barely show the existence of the cloud layer as it is rather shallow. Table 4 provides an overview of the observed and simulated cloud boundaries between 11:00 and 12:00 UTC. An average of Cloudnet observations at LACROS and JOYCE and a ceilometer at the JOYCE site results in a $156 \mathrm{~m}$ deep layer. The cloud layer in both simulations is about 2.5 times deeper, with about $388 \mathrm{~m}$ for PALM and $419 \mathrm{~m}$ for UCLA-LES. The LESs are expected to show deeper cloud layers as the maximum height of a sampled cloud in the domain determines the depth, whereas the measurements sample at one point only. Both LES models simulate a total cloud cover during noon that is not higher than $5 \%$ (not shown) and the LWP also does not show a significant signal (see Fig. 8b), supporting the finding of a very weak shallow-cumulus layer in the models. The cloud boundaries are also depicted in Fig. 9d-f as gray and green dashed layers for the LES. The cloud boundaries from observations at KITcube are not shown as it was not possible to reliably estimate them from the lidars at the KITcube site.
There were only four tiny clouds that passed the lidars during the $1 \mathrm{~h}$ period (not shown). Note that the cloud layers are also scaled, which might lead to a different impression while comparing the thicknesses.

The variances on 5 May also show no distinct feature of a well-developed cumulus layer on top of a well-mixed subcloud layer in the LES as well as in the observations. Their shapes strongly resemble those of the variances in the cloudfree convective boundary layer discussed before. For the vertical velocity variance, the LES horizontal mean as well as most of the virtual measurements are close to the uncertainty range of the lidar, also showing a shape similar to the lidar. The potential temperature variance can only be compared below $0.7 z_{i}$ as it is not available from RRL higher above. LES and lidar both show low variances in the well-mixed part of the boundary layer. The maximum of mixing ratio variance is located slightly higher than that of the LES.

Overall, the long-term LES approach is able to deliver variance (turbulence) profiles that are in a satisfactory agreement with lidar observations.

\section{Sensitivities}

To study how robust the previously discussed results are with respect to the chosen setup, the reference simulations RP and RU were complemented by 14 additional simulations with PALM. Table 5 lists the simulations with their differences in the setups relative to the setup RP and RU, which was described in Sect. 2.3. Most of these additional simulations were run on a smaller horizontal domain $\left(4.8 \times 4.8 \mathrm{~km}^{2}\right.$ instead of $48 \times 48 \mathrm{~km}^{2}$, denoted with a capital S in Table 5) and for the first 3 days only (24-26 April) for the sake of compu- 
Table 4. Simulated and observed cloud boundaries on 5 May 2013 for 11:00-12:00 UTC.

\begin{tabular}{lrrrrr}
\hline & PALM & UCLA-LES & Cloudnet (LA) & Cloudnet (JO) & Ceilometer (JO) \\
\hline$z_{\mathrm{cb}}(\mathrm{m})$ & $1333 \pm 40$ & $1294 \pm 43$ & $1464 \pm 112$ & $1546 \pm 178$ & $1365 \pm 49$ \\
$z_{\mathrm{ct}}(\mathrm{m})$ & $1721 \pm 83$ & $1713 \pm 62$ & $1594 \pm 118$ & $1735 \pm 196$ & $1526 \pm 56$ \\
$d_{\mathrm{c}}(\mathrm{m})$ & $388 \pm 58$ & $419 \pm 33$ & $133 \pm 60$ & $189 \pm 146$ & $171 \pm 53$ \\
$N$ & 13 & 13 & 33 & 21 & 125 \\
\hline
\end{tabular}

Values include mean and standard deviation over 11:00-12:00 UTC. Cloud boundaries in LESs are determined based on horizontally averaged profiles of cloud liquid water. Cloud-base height, cloud-top height and cloud-layer depth are denoted by $z_{\mathrm{cb}}, z_{\mathrm{ct}}$ and $d_{\mathrm{c}}$, respectively. The number of samples entering the averaging period is $N$. See Table 1 for an overview of the observations used.

Table 5. Parameters of the simulated cases.

\begin{tabular}{|c|c|c|c|c|c|c|c|c|c|c|}
\hline Case & LES model & $\begin{array}{r}\Delta \\
\text { (m) }\end{array}$ & $\begin{array}{c}L_{1} \times L_{2} \\
(\mathrm{~km})\end{array}$ & $N_{1} \times N_{2} \times N_{3}$ & $\begin{array}{c}z_{0} \\
(\mathrm{~m})\end{array}$ & $\begin{array}{r}t_{\text {sim }} \\
\text { (day) }\end{array}$ & $\begin{array}{r}\tau \\
(\mathrm{h})\end{array}$ & $\begin{array}{r}L_{\mathrm{COSMO}} \\
\left({ }^{\circ}\right)\end{array}$ & $\begin{array}{c}\mathcal{T}_{\text {COSMO }} \\
\text { (h) }\end{array}$ & Surface BC \\
\hline $\mathrm{RP}$ & PALM & 50 & $48 \times 48$ & $960 \times 960 \times 144$ & 0.45 & 19 & 6 & 2.0 & 3 & prescr. $\theta$ and $q_{\mathrm{v}}$ \\
\hline RU & UCLA & 50 & $48 \times 48$ & $960 \times 960 \times 144$ & 0.45 & 19 & 6 & 2.0 & 3 & prescr. $\theta$ and $q_{\mathrm{v}}$ \\
\hline RPS & PALM & 50 & $4.8 \times 4.8$ & $96 \times 96 \times 144$ & 0.45 & 19 & 6 & 2.0 & 3 & prescr. $\theta$ and $q_{\mathrm{v}}$ \\
\hline RUS & UCLA & 50 & $4.8 \times 4.8$ & $96 \times 96 \times 144$ & 0.45 & 19 & 6 & 2.0 & 3 & prescr. $\theta$ and $q_{\mathrm{v}}$ \\
\hline F0.25 & PALM & 50 & $4.8 \times 4.8$ & $96 \times 96 \times 144$ & 0.27 & 3 & 6 & 0.25 & 3 & prescr. $\theta$ and $q_{\mathrm{v}}$ \\
\hline F0.5 & PALM & 50 & $4.8 \times 4.8$ & $96 \times 96 \times 144$ & 0.31 & 3 & 6 & 0.5 & 3 & prescr. $\theta$ and $q_{\mathrm{v}}$ \\
\hline F1.0 & PALM & 50 & $4.8 \times 4.8$ & $96 \times 96 \times 144$ & 0.41 & 3 & 6 & 1.0 & 3 & prescr. $\theta$ and $q_{\mathrm{v}}$ \\
\hline F3.0 & PALM & 50 & $4.8 \times 4.8$ & $96 \times 96 \times 144$ & 0.44 & 3 & 6 & 3.0 & 3 & prescr. $\theta$ and $q_{\mathrm{v}}$ \\
\hline $\mathrm{F} 4.0$ & PALM & 50 & $4.8 \times 4.8$ & $96 \times 96 \times 144$ & 0.40 & 3 & 6 & 4.0 & 3 & prescr. $\theta$ and $q_{\mathrm{v}}$ \\
\hline TR1 & PALM & 50 & $4.8 \times 4.8$ & $96 \times 96 \times 144$ & 0.45 & 3 & 6 & 2.0 & 1 & prescr. $\theta$ and $q_{\mathrm{v}}$ \\
\hline Nno & PALM & 50 & $4.8 \times 4.8$ & $96 \times 96 \times 144$ & 0.45 & 19 & $\infty$ & 2.0 & 3 & prescr. $\theta$ and $q_{\mathrm{v}}$ \\
\hline N1 & PALM & 50 & $4.8 \times 4.8$ & $96 \times 96 \times 144$ & 0.45 & 19 & 1 & 2.0 & 3 & prescr. $\theta$ and $q_{\mathrm{v}}$ \\
\hline N12 & PALM & 50 & $4.8 \times 4.8$ & $96 \times 96 \times 144$ & 0.45 & 19 & 12 & 2.0 & 3 & prescr. $\theta$ and $q_{\mathrm{v}}$ \\
\hline FLX & PALM & 50 & $4.8 \times 4.8$ & $96 \times 96 \times 144$ & 0.45 & 19 & 6 & 2.0 & 3 & prescr. fluxes \\
\hline RPS12.5 & PALM & 12.5 & $4.8 \times 4.8$ & $384 \times 384 \times 480$ & 0.45 & 3 & 6 & 2.0 & 3 & prescr. $\theta$ and $q_{\mathrm{v}}$ \\
\hline RPS25 & PALM & 25 & $4.8 \times 4.8$ & $192 \times 192 \times 266$ & 0.45 & 3 & 6 & 2.0 & 3 & prescr. $\theta$ and $q_{\mathrm{v}}$ \\
\hline RPS100 & PALM & 100 & $4.8 \times 4.8$ & $48 \times 48 \times 84$ & 0.45 & 3 & 6 & 2.0 & 3 & prescr. $\theta$ and $q_{\mathrm{v}}$ \\
\hline
\end{tabular}

$\Delta$ denotes the grid spacing. $L_{1}$ and $L_{2}$ are the model domain sizes in $x_{1}$ and $x_{2}$ directions, respectively. $N_{1}, N_{2}$ and $N_{3}$ are the number of grid points in $x_{1}, x_{2}$ and $x_{3}$ directions, respectively. $z_{0}$ is the roughness length for momentum. $t_{\mathrm{sim}}$ is the simulation time. $\tau$ is the relaxation timescale. $L_{\mathrm{COSMO}}$ is the averaging domain size of the larger-scale forcing data (given in degrees on the geographical grid). $\mathcal{T}_{\text {COSMO }}$ is the temporal resolution of the larger-scale forcing data. The abbreviations surface BC and prescr. stand for surface boundary conditions and prescribed, respectively.

tational resources. Note that RP and RU ran on 2000 cores for around 7 and 10 days, respectively. The period 24-26 April was chosen as it contains three different boundary layer states (clear sky, shallow clouds and frontal passage) in a row, being a condensed representative of the longer period.

To compare all the experiments, a metric based on the boundary layer depth (see Fig. 5) is constructed. As $z_{i}$ is a central quantity for evaluating mean boundary layer characteristics, it is chosen as a basis for the metric. For each available value, the absolute difference in boundary layer depth of PALM between the host model COSMO, the aerosol lidar Polly and the wind lidar HALO, respectively, are calculated. Then, an average over the number of available daily time spans from 12:00 to 14:00 UTC (either 19 or 3 depending on the case) is taken and the standard deviation is provided accordingly. This metric is called mean peak difference to PALM in the following. A daily averaging time span of $2 \mathrm{~h}$ (12:00-14:00 UTC) was chosen to consider the state of a well-developed boundary layer in a quasi-steady period. Figure 10 shows the mean peak difference in boundary layer depth to PALM for all the additional simulations. At a first glance it can be noted that the mean peak differences to PALM of COSMO, Polly and HALO show the same behavior in most cases. The metric based on the wind lidar HALO usually shows the highest and positive values, meaning that the peak boundary layer depth of PALM is usually higher than the one measured by HALO.

Comparing the 19-day reference simulation RP with the 19-day simulation RPS, which was conducted on the small horizontal domain, we note that the domain size has virtually 
no effect on the mean peak difference to PALM (Fig. 10a, comparing cases RP and RPS , 19d). Thus, robust first-order statistics are gained even in case the domain size is significantly smaller than in the reference case. This finding suggests that the mesoscale circulations that can develop internally on a $50 \mathrm{~km} \times 50 \mathrm{~km}$ domain without orography and surface heterogeneity are not particularly important.

A fundamental parameter of the larger-scale forcing method is the averaging domain size for the applied forcing data $L_{\text {COSMO }}$, specified in degrees on the geographical grid (see also Appendix A). For the reference runs RP and $\mathrm{RU}$, a size of $L_{\mathrm{COSMO}}=2.0^{\circ}$ was used. To evaluate whether the size of the averaging box is appropriate to represent larger-scale processes, the simulations F0.25, F0.5, F1.0, F3.0 and F4.0 (see Table 5) were conducted, where the COSMO averaging domain sizes varied from 0.25 to $4.0^{\circ}$, which corresponds to horizontal extensions $\mathcal{D}_{x} \times \mathcal{D}_{y}$ of $17.5 \times 27.8$ to $280 \times 444 \mathrm{~km}^{2}$ being equivalent to averaging over $10 \times 10$ to $160 \times 160$ COSMO grid points. The averaging domain size of the COSMO forcing has a large impact on the boundary layer depth as can be seen in Fig. 10b. Especially the two smallest averaging domain sizes produce large discrepancies in peak boundary layer depth to the estimates of $z_{i}$ stemming from Polly and HALO lidar. Thus, as the averaging area gets small, more mesoscale flows, which COSMO does not necessarily represent well, are sampled. Nonetheless, mean boundary layer characteristics become less sensitive if a $2.0^{\circ}$ or larger averaging domain size is used. Cloud structures and precipitation depend more strongly on the averaging domain size of the forcing (not shown). Overall, the averaging domain should have a size that is large enough to not include mesoscale fluctuations on the one side and that is small enough to still account for a localized, representative area like the HOPE region.

The temporal resolution of the forcing data is $3 \mathrm{~h}$, which also includes the prescribed surface temperature and humidity and via Monin-Obukhov similarity theory the surface fluxes. However, boundary layer timescales are usually much shorter (the turnover timescale is about $10 \mathrm{~min}$ around noon for the presented period). As the simulations are strongly determined by the imposed surface fluxes, the question of whether prescribing new surface values every $3 \mathrm{~h}$ is too infrequent to impose the signal of a proper diurnal cycle was posed. Thus, the simulation TR1 was performed, where forcing data with a temporal resolution of $1 \mathrm{~h}$ were used. As the larger-scale horizontal and vertical advective forcing act on larger timescales than the surface forcing, a higher temporal resolution should affect the surface fluxes most. Comparing the cases RPS (3d) and TR1 shown in Fig. 10a, it can be noticed that the metrics are nearly identical. The higher temporal resolution seems to bring no additional value. Hence, it is concluded that a 3-hourly forcing data set is sufficient to impose a proper diurnal cycle in the simulations.

As nudging (Newtonian relaxation) does not represent a real physical process (Randall and Cripe, 1999), it was
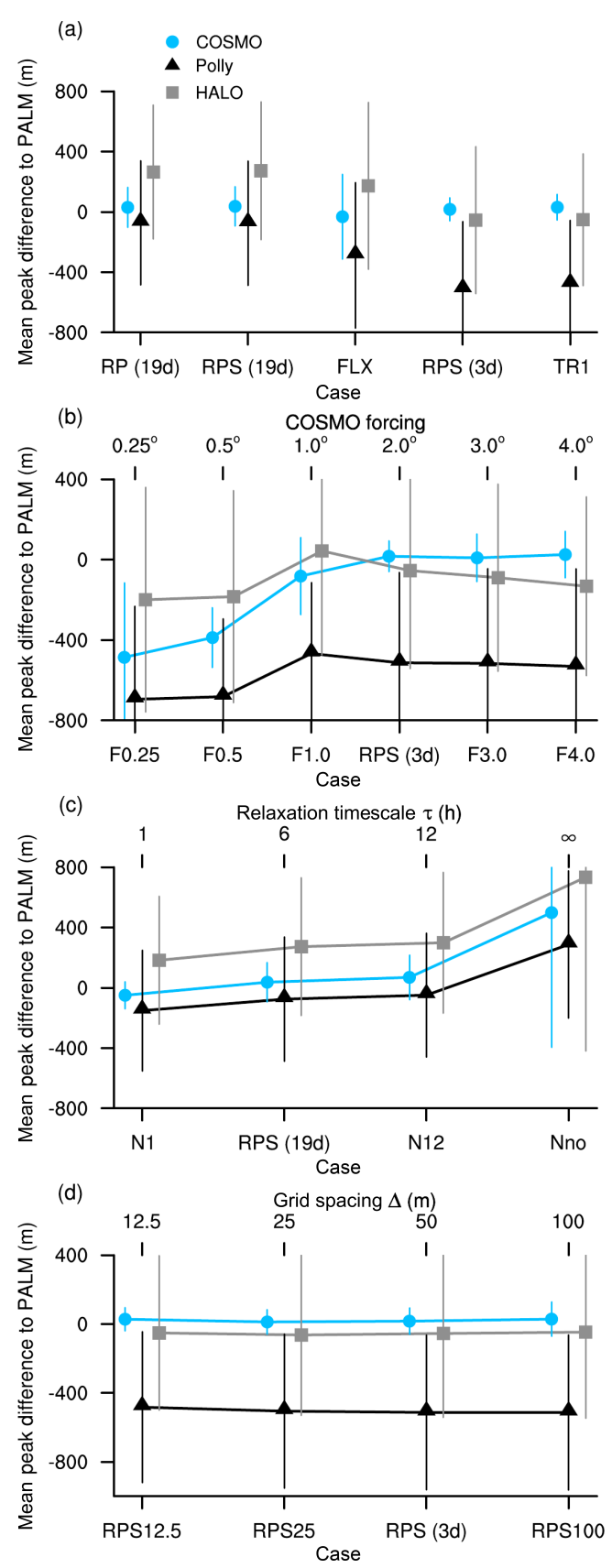

Figure 10. Mean peak difference in boundary layer depth to PALM between 12:00 and 14:00 UTC for the simulated cases listed in Table 5. Standard deviations are provided along with the means. Panels (b)-(d) include the mean peak difference for the sensitivity experiments about the averaging size of the COSMO forcing, the nudging timescale and the grid spacing, respectively. Panel (a) lists the remaining cases. Note that the mean peak difference of the PALM reference run on the small domain (RPS) is calculated over the whole 19 days (RPS, 19d) and the 3-day testing period (RPS, $3 d)$. The number of values entering the average are $(38,147$ and $464)$ for 19 -day runs and $(6,38$ and 78$)$ for 3 -day runs. The tuples denote the number of values entering the mean of the difference in boundary layer depth to COSMO, Polly and HALO. 
analyzed how crucially the results depend on the nudging timescale and on the nudging itself. Three additional simulations were performed where a stronger nudging with $\tau=1 \mathrm{~h}$ (case N1), a weaker nudging with $\tau=12 \mathrm{~h}$ (case N12) and no nudging at all ( $\tau \rightarrow \infty$, case Nno) compared to the reference nudging timescale of $6 \mathrm{~h}$ were used. The simulation without nudging can also be interpreted as a simulation where the radiative forcing is completely switched off as the effect of radiation is indirectly mimicked via the relaxation (see Sect. 2.3). The mean peak difference to PALM (Fig. 10c) shows only a weak dependence for $\tau \leq 12 \mathrm{~h}$. In the case where Newtonian relaxation is completely turned off, the mean peak difference to PALM increases strongly. In this case PALM strongly overestimates the boundary layer depth compared to the forcing and the observations. The overall performance of the simulation becomes worse. This analysis shows that using nudging with reasonable nudging timescales of several hours is beneficial for the long-term LES framework. Furthermore, the mean boundary layer characteristics barely depend on the actual choice of the nudging timescale supporting the robustness of the setup.

To test the impact of the individual larger-scale forcing components, several tests were made in which the forcing components were mutually switched off and then added one after the other (not shown). These tests suggested that all components should be used in combination for obtaining the best results with respect to the observations. This is in agreement with the single-column model study of Sterk et al. (2015), where they studied the realistic simulation of clearsky stable boundary layers over snow-covered surfaces.

In the reference setup, Dirichlet conditions are used at the surface, meaning that potential temperature and mixing ratio are prescribed at the surface. The alternative is to prescribe surface fluxes directly (using Neumann boundary conditions). The latter was used in the case of FLX. Overall, the prescribed surface fluxes are slightly smaller and show a time lag in respect to the fluxes that are calculated in the case of RPS (19d) (not shown). Comparing the cases RPS (19d) and FLX concerning the mean peak difference to PALM (Fig. 10a), it can be seen that the metric for COSMO changes only marginally and that the metric for Polly deteriorates, whereas the metric for HALO improves. Also taking the arguments of Basu et al. (2008) into account that for modeling stable boundary layers prescribing surface fluxes should be avoided, we think prescribing surface values is the better option, as during the multiple-day LES stable regimes that we conducted and simulated to a considerable fraction.

To evaluate the influence of the numerical grid spacing, the 3-day simulation RPS (3d) with an isotropic grid spacing $\Delta=50 \mathrm{~m}$ was rerun using two finer grid spacings ( $\Delta=25 \mathrm{~m}$ called RPS25 and $\Delta=12.5 \mathrm{~m}$ called RPS12.5) and one coarser grid spacing ( $\Delta=100 \mathrm{~m}$ called RPS100). Only minor differences were observed between the runs in the time series of the boundary layer depth, which mainly occur during nighttime. This indicates that the differences between the runs are closely linked to their different capabilities of resolving the shallow stable boundary layer at night. The influence on the better resolved nighttime stable boundary layer on the following convective day is rather small as van Stratum and Stevens (2015) already showed. The simulated clouds also do not show any dependence on the grid spacing. Figure 10d shows that the influence of the grid spacing on mean boundary layer characteristics is negligible in terms of the mean peak difference metric.

\section{Summary and conclusions}

In this study long-term LESs with PALM and UCLA-LES are evaluated to assess the ability of LES in a semi-idealized setup to simulate observed characteristics of boundary layer turbulence. The semi-idealized approach consists of using periodic lateral boundary conditions and a homogeneous surface together with prescribing time-dependent larger-scale forcing and nudging deduced from the mesoscale numerical weather prediction model COSMO to account for the synoptic conditions at a specific location. A continuous period of 19 days of the HOPE measurement campaign is chosen and the simulation results are compared to the multi-sensor HOPE data set. The three principal measurement sites of HOPE enable a more representative view on the larger observational area. This circumstance facilitates the comparison to the LES, which, by construction, can only deliver a flow that is representative for the HOPE region. The analysis focuses on key boundary layer quantities like the boundary layer depth, near-surface temperatures and winds, integrated quantities like IWV and LWP, and turbulence statistics in terms of variance profiles. A metric based on the peak boundary layer depth is used to compare several sensitivity runs. With these additional simulations the robustness of the reference setup is investigated.

The (unphysical) nudging tendency, which prevents model drift in time, is generally less important compared to largerscale horizontal and vertical advective tendencies. The exceptions are cases with strong larger-scale forcing; then the nudging tendencies can be significant.

The reference simulation shows reasonable agreement with the HOPE measurements. The principal character of the day (weather situation) can be reproduced by the LES in about $80 \%$ of the cases. Simulating cloud-topped boundary layers correctly is a challenge for the long-term LES. The daily development of the boundary layer depth is in principal agreement with lidar measurements. The LES surface fluxes are in a rough agreement with the weighted, averaged surface fluxes in the HOPE area showing that the surface forcing is representative for the HOPE area. Both LES models used produce very similar results.

The LES models seem to track COSMO closely and deviate from the observations in a similar fashion as COSMO does. This can be interpreted in two ways. Either deviations 
from the observations are inherited from the host model or they represent the signature of mesoscale forcing that the present approach is incapable of capturing. By using LES in a more realistic setup with open boundary conditions, these hypotheses might be tested.

LES turbulence statistics in terms of variance profiles are in satisfactory agreement with lidar measurements during HOPE. The peak in scalar variances at the top of the boundary layer is underestimated by LES, indicating that presumably the resolution used in the LES is rather coarse for correctly representing strong gradients and that heterogeneity is missing.

The chosen semi-idealized setup is insensitive to the horizontal domain size, the grid spacing, the temporal resolution of the forcing data and the surface boundary condition in terms of mean boundary layer characteristics. Thus, the internally generated mesoscale circulation on a larger domain is not particularly important and the character of the biases is not strongly dependent on the model or how the forcing is applied. There is a dependence on the averaging size of the forcing data. If the averaging domain is large enough and mesoscale fluctuations are sufficiently filtered out, the results converge. Using nudging itself to prevent model drift in time is important. The actual value for the relaxation timescale is of minor importance provided that it is of the order of several hours.

As the semi-idealized setup stably represents a wide range of observed weather situations, it is also applicable as superparameterization (Grabowski, 2016) in a global model. It would be interesting to study how the overall performance of a global model with superparameterization depends on the chosen grid size, which is tied to the horizontal domain size of the imbedded LES. As the LESs obtain mean forcing profiles from the global model, the overall domain size from which the forcing is constructed might play a role as the semi-idealized setup depends on the averaging size of the forcing data.
The long-term LES approach cannot only be used to simulate periods at meteorological super sites like in Schalkwijk et al. (2015) but also for simulating periods of (or even whole) measurement campaigns to support the interpretation of measurement results. This approach has been adopted for the Next-generation Aircraft Remote Sensing for Validation (NARVAL) series of flight campaigns over the tropical Atlantic (Klepp et al., 2014; Stevens et al., 2016) and is being followed in the LES ARM Symbiotic Simulation and Observation (LASSO) project (http://www.arm.gov/science/ themes/lasso), where continuous LES of the southern Great Plains atmospheric radiation measurement (ARM) super site are under development.

One strength of the semi-idealized approach is that it is able to deliver robust turbulence statistics and a good representation of clouds, as is typical for LES, and that it accounts for a localized area responding to everyday weather. However, a certain variability coming from the heterogeneous surface that usually surrounds any real observational site is neglected in the LES. The semi-idealized long-term LES approach can also be seen as an intermediate step towards LES in a limited-area setup, where, for example, a land-surface model and interactive radiation are used. In the framework of $\mathrm{HD}(\mathrm{CP})^{2}$, these kinds of simulations are performed over Germany. They are compared to the semi-idealized simulations presented here and the HOPE data set in Heinze et al. (2017). Comparing LES in semi-idealized and limited-area setups also allows the quantification of the role of the mesoscale.

Data availability. Primary data and scripts used in the analysis and other supplementary information that may be useful in reproducing the author's work are archived by the German Climate Computing Center and can be obtained at https://cera-www.dkrz.de/WDCC/ui/ Entry.jsp?acronym=DKRZ_LTA_974_ds00001 (Heinze, 2017). 


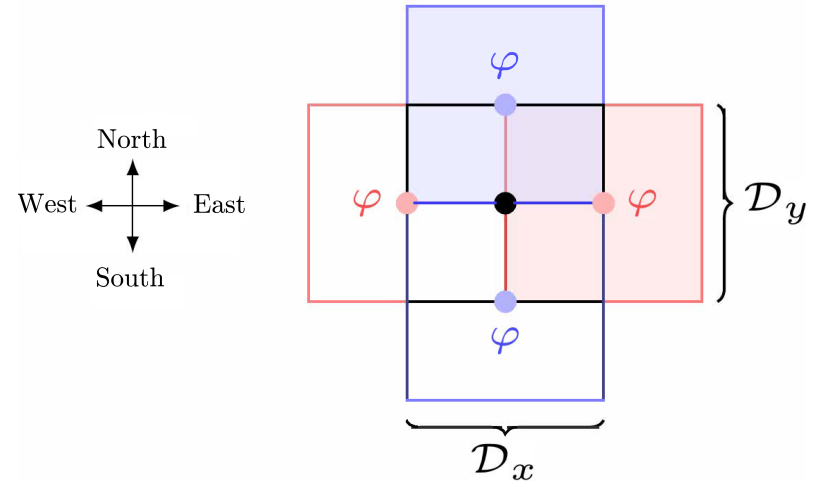

Figure A1. Averaging concept for the determination of larger-scale forcing terms from COSMO model output. The shifted domains (red and blue) are used for the calculation of larger-scale gradients of $\phi \in\left\{\theta_{1, \mathrm{LS}}, q_{\mathrm{t}, \mathrm{LS}}\right\}$. The centered averaging domain (black) is used for the calculation of all other larger-scale quantities.

\section{Appendix A: Construction of forcing data}

To filter out any impact of small-scale phenomena in the forcing data, the COSMO (Baldauf et al., 2011) analysis data (with a spatial and temporal resolution of $2.8 \mathrm{~km}$ and $3 \mathrm{~h}$, respectively) we used are averaged spatially. Note that the semi-idealized LES approach requires vertical profiles of geostrophic wind components $u_{\mathrm{g}, i}$, of larger-scale velocity vector $\boldsymbol{u}_{i, \mathrm{LS}}$, of liquid water potential temperature $\theta_{1, \mathrm{LS}}$, of total water mixing ratio $q_{\mathrm{t}, \mathrm{LS}}$, and of larger-scale gradients (horizontal and vertical) of $\theta_{1, \mathrm{LS}}$ and $q_{\mathrm{t}, \mathrm{LS}}$ (see Eqs. 1-4). Moreover, corresponding surface conditions of temperature, humidity (or the respective sensible and latent heat fluxes) and hydrostatic pressure (which is important for cloud microphysics) are needed.
First, a spatial averaging domain with side lengths $\mathcal{D}_{x}$ (zonal) and $\mathcal{D}_{y}$ (meridional) is defined. These side lengths should be large enough to filter the small scales (see Sect. 5 for a discussion of adequate averaging domain sizes). For determining the entire set of larger-scale quantities required for the long-term LES approach, five averaging domains are needed, as shown in Fig. A1:

- One centered domain (black square) for the determination of surface conditions and vertical profiles of $u_{\mathrm{g}, i}$, $u_{i, \mathrm{LS}}, \theta_{\mathrm{l}, \mathrm{LS}}$ and $q_{\mathrm{t}, \mathrm{LS}}$ is needed.

- Four shifted domains (red and blue squares) for the determination of larger-scale horizontal gradients of $\theta_{1, \mathrm{LS}}$ and $q_{\mathrm{t}, \mathrm{LS}}$ are needed.

The averaged quantities of the centered domain are then assumed to represent the large-scale quantities in the LES. The centers of the shifted domains are located one-half $\mathcal{D}_{x}$ in the east-west direction and one-half $\mathcal{D}_{y}$ in the north-south direction. Hence, the larger-scale gradients used in Eq. (2) are approximated as follows:

$$
\begin{aligned}
\frac{\partial \varphi_{\mathrm{LS}}}{\partial x_{1}} & =\frac{\varphi_{\mathrm{LS}, \text { east }}-\varphi_{\mathrm{LS}, \text { west }}}{\mathcal{D}_{x}} \\
\frac{\partial \varphi_{\mathrm{LS}}}{\partial x_{2}} & =\frac{\varphi_{\mathrm{LS}, \text { north }}-\varphi_{\mathrm{LS}, \text { south }}}{\mathcal{D}_{y}}
\end{aligned}
$$

since the averaged quantities are assumed to represent the larger-scale conditions at the center of each domain. 
Competing interests. The authors declare that they have no conflict of interest.

Acknowledgements. This study was supported by the Federal Ministry of Education and Research in Germany (Bundesministerium für Bildung und Forschung, BMBF) through the research program "High Definition Clouds and Precipitation for Climate Prediction HD $(C P)^{2}$ " (specifically grants 01LK1203B and 01LK1203A). The simulations were performed on the Cray XC30/40 of the NorthGerman Supercomputing Alliance (HLRN) in Hanover and Berlin, Germany, and on the IBM Power6 of the German Climate Computing Center (DKRZ) in Hamburg, Germany. The NCAR command language (version 6.3.0, http://dx.doi.org/10.5065/D6WD3XH5) was used for analysis and visualization.

We thank D. Klocke (Deutscher Wetterdienst) for providing the COSMO larger-scale forcing data, R. Neggers (Universität zu Köln) for a discussion about how to derive the larger-scale forcing data from COSMO, H. Knoop (Leibniz Universität Hannover) for his support in generating the volume-rendered visualization used in Fig. 3 with VAPOR (http://www.vapor.ucar.edu), M. Schmidt (Forschungszentrum Jülich) for providing the surface fluxes from the TERENO sites, H. Baars (Leibniz Institut für Troposphärenforschung) for providing the boundary layer depth data from aerosol lidar Polly ${ }^{X T}$, U. Löhnert (Universität zu Köln) for providing the boundary layer depth data from the wind lidar HALO and Cloudnet data for JOYCE, P. Seifert (Leibniz Institut für Troposphärenforschung) for providing the Cloudnet data for JOYCE, A. Knaps (Forschungszentrum Jülich) for providing the data from the meteorological tower at JOYCE, A. Lammert-Stockschläder (Universität Hamburg) and V. Grützun (Universität Hamburg) for continuous support with the measurement data sets through the Standardized Atmospheric Measurement Data (SAMD) archive (https://icdc.cen.uni-hamburg.de/index.php?id=samd; http://doi.org/10.17616/R3D944), and the $\mathrm{HD}(\mathrm{CP})^{2}$ teams of KIT Karlsruhe and Universität zu Köln for launching radiosondes. We also thank the University of Hohenheim lidar team, A. Behrendt, F. Späth, E. Hammann, A. Reide and V. Wulfmeyer, for providing the lidar measurements during the HOPE campaign; Alberto de Lozar (Deutscher Wetterdienst) for comments on an earlier version of the paper and the two anonymous reviewers whose comments helped to improve the paper.

The article processing charges for this open-access publication were covered by the Max Planck Society.

Edited by: Herman Russchenberg

Reviewed by: two anonymous referees

\section{References}

Althausen, D., Engelmann, R., Baars, H., Heese, B., Ansmann, A., Müller, D., and Komppula, M.: Portable Raman lidar Polly ${ }^{X T}$ for automated profiling of aerosol backscatter, extinction, and depolarization, J. Atmos. Ocean. Tech., 26, 2366-2378, https://doi.org/10.1175/2009JTECHA1304.1, 2009.

Ansorge, C. and Mellado, J. P.: Global intermittency and collapsing turbulence in the stratified planetary boundary layer, Bound.Lay. Meteorol., 153, 89-116, https://doi.org/10.1007/s10546014-9941-3, 2014.

Ansorge, C. and Mellado, J. P.: Analyses of external and global intermittency in the logarithmic layer of Ekman flow, J. Fluid Mech., 805, 611-635, https://doi.org/10.1017/jfm.2016.534, 2016.

Anthes, R. A.: Data assimilation and initialization of hurricane prediction models, J. Atmos. Sci., 32, 702-719, 1974.

Arakawa, A. and Lamb, V. R.: Computational design of the basic dynamical processes of the UCLA general cirulation model, in: vol. 17, General circulation models of the atmosphere, edited by: Chang, J., Elsevier, 173-265, 1977.

ASTER GDEM Validation Team: ASTER global digital elevation model version 2 - summary of validation results, Tech. rep., NASA Land Processes Distributed Active Archive Center (LP DAAC), USGS/Earth Resources Observation and Science (EROS) Center, Sioux Falls, South Dakota, USA, http://www.jspacesystems.or.jp/ersdac/GDEM/ver2Validation/ Summary_GDEM_validation_report_final.pdf (last access: 2 June 2016), 2011.

Baars, H., Ansmann, A., Engelmann, R., and Althausen, D.: Continuous monitoring of the boundary-layer top with lidar, Atmos. Chem. Phys., 8, 7281-7296, https://doi.org/10.5194/acp-8-72812008, 2008.

Baas, P., Bosveld, F., Lenderink, G., van Meijgaard, E., and Holts, A. A. M.: How to design single-column model experiments for comparison with observed nocturnal low-level jets, Q. J. Roy. Meteorol. Soc., 136, 671-684, https://doi.org/10.1002/qj.592, 2010.

Baldauf, M., Seifert, A., Förstner, J., Majewski, D., Raschendorfer, M., and Reinhardt, T.: Operational convective-scale numerical weather prediction with the COSMO model: description and sensitivities, Mon. Weather Rev., 139, 3887-3905, https://doi.org/10.1175/MWR-D-10-05013.1, 2011.

Basu, S., Holtslag, A. A. M., van de Wiel, B. J. H., Moene, A., and Steeneveld, G.-J.: An inconvenient 'truth' about using sensible heat flux as a surface boundary condition in models under stably stratified regimes, Acta Geophys., 56, 88-99, https://doi.org/10.2478/s11600-007-0038-y, 2008.

Basu, S., Holtslag, A., Caporaso, L., Riccio, A., and Steeneveld, G.J.: Observational support for the stability dependence of the bulk Richardson number across the stable boundary layer, Bound.Lay. Meteorol., 150, 515-523, https://doi.org/10.1007/s10546013-9878-y, 2014.

Beare, R. J., Macvean, M. K., Holtslag, A. A. M., Cuxart, J., Esau, I., Golaz, J.-C., Jimenez, M. A., Khairoutdinov, M., Kosovic, B., Lewellen, D., Lund, T. S., Lundquist, J. K., Mccabe, A., Moene, A. F., Noh, Y., Raasch, S., and Sullivan, P. P.: An intercomparison of large-eddy simulations of the stable boundary layer, Bound.Lay. Meteorol., 118, 247-272, 2006. 
Behrendt, A., Wulfmeyer, V., Hammann, E., Muppa, S. K., and Pal, S.: Profiles of second- to fourth-order moments of turbulent temperature fluctuations in the convective boundary layer: first measurements with rotational Raman lidar, Atmos. Chem. Phys., 15, 5485-5500, https://doi.org/10.5194/acp-15-5485-2015, 2015.

Bosveld, F. C., Baas, P., van Meijgaard, E., de Bruijn, E. I. F., Steeneveld, G.-J., and Holtslag, A. A. M.: The third GABLS intercomparison case for evaluation studies of boundary-layer models. Part A: Case selection and set-Up, Bound.-Lay. Meteorol., 142, 133-156, https://doi.org/10.1007/s10546-014-9917-3, 2014.

Brown, A. R., Cederwall, R. T., Chlond, A., abd J.-C. Golaz, P. G. D., Khairoutdinov, M., Lewellen, D. C., Lock, A. P., MacVean, M. K., Moeng, C.-H., Neggers, R. A. J., Siebesma, A. P., and Stevens, B.: Large-eddy simulation of the diurnal cycle of shallow cumulus convection over land, Q. J. Roy. Meteorol. Soc., 128, 1075-1094, https://doi.org/10.1256/003590002320373210, 2002.

Brutsaert, W.: The roughness length for water vapor sensible heat, and other scalars, J. Atmos. Sci., 32, 2029-2031, 1975.

Bühl, J., Seifert, P., Wandinger, U., Baars, H., Kanitz, T., Schmidt, J., Myagkov, A., Engelmann, R., Skupin, A., Heese, B., Klepel, A., Althausen, D., and Ansmann, A.: LACROS: the Leipzig Aerosol and Cloud Remote Observations System, Remote Sensing of Clouds and the Atmosphere XVIII; and Optics in Atmospheric Propagation and Adaptive Systems XVI, Proc. SPIE 8890, 889002, https://doi.org/10.1117/12.2030911, 2013.

Clyne, J., Mininni, P., Norton, A., and Rast, M.: Interactive desktop analysis of high resolution simulations: application to turbulent plume dynamics and current sheet formation, New J. Phys., 9, 301, 2007.

Cuijpers, J. W. M. and Duynkerke, P. G.: Large eddy simulation of trade wind cumulus clouds, J. Atmos. Sci., 50, 3894-3908, https://doi.org/10.1175/15200469(1993)050<3894:LESOTW>2.0.CO;2, 1993.

Deardorff, J. W.: Convective velocity and temperature scales for the unstable planetary boundary layer and for Rayleigh convection, J. Atmos. Sci., 27, 1211-1213, https://doi.org/10.1175/15200469(1970)027<1211:CVATSF>2.0.CO;2, 1970a.

Deardorff, J. W.: Preliminary results from numerical integrations of the unstable planetary boundary layer, J. Atmos. Sci., 27, 1209-1211, https://doi.org/10.1175/15200469(1970)027<1209:PRFNIO>2.0.CO;2, 1970b

Deardorff, J. W.: Numerical Investigation of Neutral and Unstable Planetary Boundary Layers, J. Atmos. Sci., 29, 91-115, https://doi.org/10.1175/15200469(1972)029<0091:NIONAU>2.0.CO;2, 1972.

Deardorff, J. W.: On the entrainment rate of a stratocumulustopped mixed layer, Q. J. Roy. Meteorol. Soc., 102, 563-582, https://doi.org/10.1002/qj.49710243306, 1976.

Deardorff, J. W.: Stratocumulus-capped mixed layers derived from a three-dimensional model, Bound.-Lay. Meteorol., 18, 495-527, https://doi.org/10.1007/BF00119502, 1980.

Durran, D. R.: Numerical methods for wave equations in geophysical fluid dynamics, Springer-Verlag, New York, 1999.

Dutton, J. A. and Fichtl, G. H.: Approximate equations of motion for gases and liquids, J. Atmos. Sci., 26, 241-254, https://doi.org/10.1175/15200469(1969)026<0241:AEOMFG>2.0.CO;2, 1969.
Edwards, J. M., Basu, S., Bosveld, F. C., and Holtslag, A. A. M.: The impact of radiation on the GABLS3 large-eddy simulation through the night and during the morning transition, Bound.Lay. Meteorol., 152, 189-211, https://doi.org/10.1007/s10546013-9895-x, 2014.

Engelmann, R., Kanitz, T., Baars, H., Heese, B., Althausen, D., Skupin, A., Wandinger, U., Komppula, M., Stachlewska, I. S., Marinou, V. A. E., Mattis, I., Linné, H., and Ansmann, A.: The automated multiwavelength Raman polarization and water-vapor lidar PollyXT: the neXT generation, Atmos. Meas. Tech., 9, 1767-1784, https://doi.org/10.5194/amt-9-1767-2016, 2016.

Grabowski, W. W.: Towards global large eddy simulation: super-parameterization revisited, J. Meteorol. Soc. Jpn., 94, https://doi.org/10.2151/jmsj.2016-017, 2016.

Grabowski, W. W., Wu, X., and Moncrieff, M. W.: Cloudresolving modeling of tropical cloud systems during phase III of GATE. Part I: Two-dimensional experiments, J. Atmos. Sci., 53, 3684-3709, https://doi.org/10.1175/15200469(1996)053<3684:CRMOTC>2.0.CO;2, 1996.

Graf, A., Schüttemeyer, D., Geiß, H., Knaps, A., Möllmann-Coers, M., Schween, J. H., Kollet, S., Neininger, B., Herbst, M., and Vereecken, H.: Boundedness of turbulent temperature probability distributions, and their relation to the vertical profile in the convective boundary layer, Bound.-Lay. Meteorol., 134, 459-486, https://doi.org/10.1007/s10546-009-9444-9, 2010.

Hammann, E., Behrend, A., Mounier, F. L., and Wulfmeye, V.: Temperature profiling of the atmospheric boundary layer with rotational Raman lidar during the $\mathrm{HD}(\mathrm{CP})-2$ Observational Prototype Experiment, Atmos. Chem. Phys., 15, 2867-2881, https://doi.org/10.5194/acp-15-2867-2015, 2015.

Harlow, F. H. and Welch, J. E.: Numerical calculation of timedependent viscous incompressible flow of fluid with free surface, Phys. Fluids, 8, 2182-2189, 1965.

Heinze, R.: Primary data and statistics used for the paper "Evaluation of large-eddy simulations forced with mesoscale model output for a multi-week period during a measurement campaign", available at: https://cera-www.dkrz.de/WDCC/ ui/Entry.jsp?acronym=DKRZ_LTA_974_ds00001, last access: 31 May 2017.

Heinze, R., Mironov, D., and Raasch, S.: Second-moment budgets in cloud-topped boundary layers: A large-eddy simulation study, J. Adv. Model. Earth Syst., 07, 510-536, https://doi.org/10.1002/2014MS000376, 2015.

Heinze, R., Dipankar, A., Henken, C. C., Moseley, C., Sourdeval, O., Trömel, S., Xie, X., Adamidis, P., Ament, F., Baars, H., Barthlott, C., Behrendt, A., Blahak, U., Bley, S., Brdar, S., Brueck, M., Crewell, S., Deneke, H., Di Girolamo, P., Evaristo, R., Fischer, J., Frank, C., Friederichs, P., Göcke, T., Gorges, K., Hande, L., Hanke, M., Hansen, A., Hege, H.-C., Hoose, C., Jahns, T., Kalthoff, N., Klocke, D., Kneifel, S., Knippertz, P., Kuhn, A., van Laar, T., Macke, A., Maurer, V., Mayer, B., Meyer, C. I., Muppa, S. K., Neggers, R. A. J., Orlandi, E., Pantillon, F., Pospichal, B., Röber, N., Scheck, L., Seifert, A., Seifert, P., Senf, F., Siligam, P., Simmer, C., Steinke, S., Stevens, B., Wapler, K., Weniger, M., Wulfmeyer, V., Zängl, G., Zhang, D., and Quaas, J.: Large-eddy simulations over Germany using ICON: a comprehensive evaluation, Q. J. Roy. Meteorol. Soc., 143, 69-100, https://doi.org/10.1002/qj.2947, 2017. 
Hoffmann, F.: The effect of spurious cloud edge supersaturations in Lagrangian cloud models: An analytical and numerical study, Mon. Weather Rev., 144, 107-118, https://doi.org/10.1175/MWR-D-15-0234.1, 2016.

Hoffmann, F., Raasch, S., and Noh, Y.: Entrainment of aerosols and their activation in a shallow cumulus cloud studied with a coupled LCM-LES approach, Atmos. Res., 156, 43-57, https://doi.org/10.1016/j.atmosres.2014.12.008, 2015.

Illingworth, A. J., Hogan, R. J., O’Connor, E. J., Bouniol, D., Delanoë, J., Pelon, J., Protat, A., Brooks, M. E., Gaussiat, N., Wilson, D. R., Donovan, D. P., Baltink, H. K., van Zadelhoff, G.-J., Eastment, J. D., Goddard, J. W. F., Wrench, C. L., Haeffelin, M., Krasnov, O. A., Russchenberg, H. W. J., Piriou, J.-M., Vinit, F., Seifert, A., Tompkins, A. M., and Willén, U.: Cloudnet, B. Am. Meteorol. Soc., 88, 883-998, https://doi.org/10.1175/BAMS-886-883, 2007.

Kalthoff, N., Adler, B., Wieser, A., Kohler, M., Träumner, K., Handwerker, J., Corsmeier, U., Khodayar, S., Lambert, D., Kopmann, A., Kunka, N., Dick, G., Ramatschi, M., Wickert, J., and Kottmeier, C.: KITcube - a mobile observation platform for convection studies deployed during HyMeX, Meteorol. Z., 22, 633647, https://doi.org/10.1127/0941-2948/2013/0542, 2013.

Klepp, C., Ament, F., Bakan, S., Hirsch, L., and Stevens, B.: The NARVAL Campaign Report, Tech. rep., Berichte zur Erdsystemforschung/Max-Planck-Institut für Meteorologie, http://hdl.handle.net/11858/00-001M-0000-0026-A6F3-7 (last access: 17 April 2017), 2014.

Lenschow, D. H., Mann, J., and Kristensen, L.: How long is long enough when measuring fluxes and other turbulence statistics, J. Atmos. Ocean. Tech., 11, 661-673, https://doi.org/10.1175/15200426(1994)011<0661:HLILEW>2.0.CO;2, 1994.

Lenschow, D. H., Wulfmeyer, V., and Senff, C.: Measuring second- through fourth-order moments in noisy data, J. Atmos. Ocean. Tech., 17, 1330-1347, https://doi.org/10.1175/15200426(2000)017<1330:MSTFOM>2.0.CO;2, 2000.

Löhnert, U., Schween, J. H., Acquistapace, C., Ebell, K., Maahn, M., Barreraverdejo, M., Hirsikko, A., Bohn, B., Knaps, A., O'connor, E., Simmer, C., Wahner, A., and Crewell, S.” JOYCE: Jülich observatory for cloud evolution, B. Am. Meteorol. Soc., 96, 1157-1174, https://doi.org/10.1175/BAMS-D-14-00105.1, 2015.

Macke, A., Seifert, P., Baars, H., Barthlott, C., Beekmans, C., Behrendt, A., Bohn, B., Brück, M., Bühl, J., Crewell, S., Damian, T., Deneke, H., Düsing, S., Foth, A., Di Girolamo, P., Hammann, E., Heinze, R., Hirsikko, A., Kalisch, J., Kalthoff, N., Kinne, S., Kohler, M., Löhnert, U., Madhavan, B. L., Maurer, V., Muppa, S. K., Schween, J., Serikov, I., Siebert, H., Simmer, C., Späth, F., Steinke, S., Träumner, K., Trömel, S., Wehner, B., Wieser, A., Wulfmeyer, V., and Xie, X.: The HD(CP)2 Observational Prototype Experiment HOPE - an overview, Atmos. Chem. Phys., 17 4887-4914, https://doi.org/10.5194/acp-17-4887-2017, 2017.

Maronga, B., Gryschka, M., Heinze, R., Hoffmann, F., KananiSühring, F., Keck, M., Ketelsen, K., Letzel, M. O., Sühring, M., and Raasch, S.: The Parallelized Large-Eddy Simulation Model (PALM) version 4.0 for atmospheric and oceanic flows: model formulation, recent developments, and future perspectives, Geosci. Model Dev., 8, 2515-2551, https://doi.org/10.5194/gmd-8-2515-2015, 2015.
Mason, P. J.: Large-eddy simulation of dispersion in convective boundary layers with wind shear, Atmos. Environ. A, 26, 15611571, https://doi.org/10.1016/0960-1686(92)90056-Q, 1992.

Mason, P. J. and Derbyshire, S. H.: Large-eddy simulation of the stably-stratified atmospheric boundary layer, Bound.-Lay. Meteorol., 53, 117-162, https://doi.org/10.1007/BF00122467, 1990.

Maurer, V., Kalthoff, N., Wieser, A., Kohler, M. M., and Gantner, L.: Observed spatial variability of boundary-layer turbulence over flat, heterogeneous terrain, Atmos. Chem. Phys., 16, 13771400, https://doi.org/10.5194/acp-16-1377-2016, 2016.

Moeng, C.-H.: A large-eddy-simulation model for the study of planetary boundary-layer turbulence, J. Atmos. Sci., 41, 2052-2062, https://doi.org/10.1175/15200469(1984)041<2052:ALESMF>2.0.CO;2, 1984.

Moeng, C.-H.: Large-eddy simulation of a stratus topped boundary layer. Part I: structure und budgets, J. Atmos. Sci., 43, 2880-2900, https://doi.org/10.1175/15200469(1986)043<2886:LESOAS>2.0.CO;2, 1986.

Moeng, C.-H. and Sullivan, P.: A comparison of shear- and buoyancy-driven planetary boundary layer flows, J. Atmos. Sci., 51, 999-1022, https://doi.org/10.1175/15200469(1994)051<0999:ACOSAB>2.0.CO;2, 1994.

Muppa, S. K., Behrendt, A., Späth, F., Wulfmeyer, V., Metzendorf, S., and Riede, A.: Turbulent humidity fluctuations in the convective boundary layer: Case studies using water vapor differential absorption lidar measurements, Bound.-Lay. Meteorol., 16, 4366, https://doi.org/10.1007/s10546-015-0078-9, 2016.

Neggers, R. A. J. and Siebesma, A. P.: Constraining a system of interacting parameterizations through multiple-parameter evaluation: tracing a compensating error between cloud vertical structure and cloud overlap, J. Climate, 26, 6698-6715, https://doi.org/10.1175/JCLI-D-12-00779.1, 2013.

Neggers, R. A. J., Siebesma, A. P., and Heus, T.: Continuous single-column model evaluation at a permanent meteorological supersite, B. Am. Meteorol. Soc., 93, 1389-1400, https://doi.org/10.1175/BAMS-D-11-00162.1, 2012.

Nieuwstadt, F. T. M. and Brost, R. A.: The decay of convective turbulence, J. Atmos. Sci., 45, 532-546, https://doi.org/10.1175/15200469(1986)043<0532:TDOCT>2.0.CO;2, 1986.

Noh, Y. W., Cheon, W. G., Hong, S. Y., and Raasch, S.: Improvement of the $k$-profile model for the planetary boundary layer based on large eddy simulation data, Bound.-Lay. Meteorol., 107, 401-427, https://doi.org/10.1023/A:1022146015946, 2003.

Ogura, Y. and Phillips, N. A.: Scale analysis of deep and shallow convection in the atmosphere, J. Atmos. Sci., 19, https://doi.org/10.1175/15200469(1962)019<0173:SAODAS>2.0.CO;2, 1962.

Pietersen, H. P., de Arellano, J. V.-G., Augustin, P., van de Boer, A., de Coster, O., Delbarre, H., Durand, P., Fourmentin, M., Gioli, B., abd F. Lohou, O. H., Lothon, M., Ouwersloot, H. G., Pino, D., and Reuder, J.: Study of a prototypical convective boundary layer observed during BLLAST: contributions by large-scale forcings, Atmos. Chem. Phys., 15, 4241-4257, https://doi.org/10.5194/acp-15-4241-2015, 2015.

Randall, D. A. and Cripe, D. G.: Alternative methods for specification of observed forcing in single-column models and cloud system models, J. Geophys. Res., 104, 24527-24545, https://doi.org/10.1029/1999JD900765, 1999. 
Richardson, H., Basu, S., and Holtslag, A.: Improving stable boundary-layer height estimation using a stability-dependent critical bulk richardson number, Bound.-Lay. Meteorol., 148, 93109, https://doi.org/10.1007/s10546-013-9812-3, 2013.

Riechelmann, T., Wacker, U., Beheng, K., Etling, D., and Raasch, S.: Influence of turbulence on the drop growth in warm clouds, Part II: Sensitivity studies with a spectral bin microphysics and a Lagrangian cloud model, Meteorol. Z., 24, 293-311, https://doi.org/0.1127/metz/2015/0608, 2015.

Rieck, M., Hohenegger, C., and Gentine, P.: The effect of moist convection on thermally induced mesoscale circulations, Q. J. Roy. Meteorol. Soc., 141, 2418-2428, https://doi.org/10.1002/qj.2532, 2015.

Saiki, E. M., Moeng, C.-H., and Sullivan, P. P.: Large-eddy simulation of the stably stratified planetary boundary layer, Bound.-Lay. Meteorol., 95, 1-30, https://doi.org/10.1023/A:1002428223156, 2000.

Schalkwijk, J., Griffith, E. J., Post, F. H., and Jonker, H. J. J.: High-performance simulations of turbulent clouds on a desktop PC: Exploiting the GPU, B. Am. Meteorol. Soc., 93, 307-314, https://doi.org/10.1175/BAMS-D-11-00059.1, 2012.

Schalkwijk, J., Jonker, H. J. J., Siebesma, A. P., and Bosveld, F. C.: A year-long large-eddy simulation of the weather over Cabauw: An overview, Mon. Weather Rev., 143, 828-844, https://doi.org/10.1175/MWR-D-14-00293.1, 2015.

Schlemmer, L. and Hohenegger, C.: Modifications of the atmospheric moisture field as a result of coldpool dynamics, Q. J. Roy. Meteorol. Soc., 142, 30-42, https://doi.org/10.1002/qj.2625, 2016.

Schween, J. H., Hirsikko, A., Löhnert, U., and Crewell, S.: Mixinglayer height retrieval with ceilometer and Doppler lidar: from case studies to long-term assessment, Atmos. Meas. Tech., 7, 3685-3704, https://doi.org/10.5194/amt-7-3685-2014, 2014.

Seifert, A.: On the parameterization of evaporation of raindrops as simulated by a one-dimensional rainshaft model, J. Atmos. Sci., 65, 3608-3619, https://doi.org/10.1175/2008JAS2586.1, 2008.

Seifert, A. and Beheng, K. D.: A double-moment parameterization for simulating autoconversion, accretion and selfcollection, Atmos. Res., 59-60, 265-281, https://doi.org/10.1016/S01698095(01)00126-0, 2001.

Seifert, A. and Beheng, K. D.: A two-moment cloud microphysics parameterization for mixed-phase clouds. Part 1: Model description, Meteorol. Atmos. Phys., 92, 45-66, https://doi.org/10.1007/s00703-005-0112-4, 2006.

Siebesma, A. P., Bretherton, C. S., Brown, A., Chlond, A., Cuxart, J., Duynkerke, P. G., Jiang, H., Khairoutdinov, M., Lewellen, D., Moeng, C.-H., Sanchez, E., Stevens, B., and Stevens, D. E.: A large eddy simulation intercomparison study of shallow cumulus convection, J. Atmos. Sci., 60, 1201-1219, https://doi.org/10.1175/15200469(2003)60<1201:ALESIS>2.0.CO;2, 2003.

Smagorinsky, J.: General circulation experiments with the primitive equations I. The basic experiment, Mon. Weather Rev., 91, 99-164, https://doi.org/10.1175/15200493(1963)091<0099:GCEWTP>2.3.CO;2, 1963.

Sommeria, G.: Three-dimensional simulation of turbulent processes in an undisturbed trade wind boundary layer, J. Atmos. Sci., 33, 216-241, https://doi.org/10.1175/15200469(1976)033<0216:TDSOTP>2.0.CO;2, 1976.
Sorbjan, Z.: Decay of convective turbulence revisited, Bound.-Lay. Meteorol., 82, 501-515, https://doi.org/10.1023/A:1000231524314, 1997.

Stauffer, D. R. and Bao, J.-W.: Optimal determination of nudging coefficients using adjoint equations, Tellus A, 45, 358-369, 1993.

Steinke, S., Eikenberg, S., Löhnert, U., Dick, G., Klocke, D., Girolamo, P. D., and Crewell, S.: Assessment of smallscale integrated water vapour variability during HOPE, Atmos. Chem. Phys., 15, 2675-2692, https://doi.org/10.5194/acp-152675-2015, 2015.

Sterk, H. A. M., Steeneveld, G. J., Vihma, T., Anderson, P. S., Bosveld, F. C., and Holtslag, A. A. M.: Clear-sky stable boundary layers with low winds over snow-covered surfaces Part I: A WRF model evaluation, Q. J. Roy. Meterorol. Soc., 141, 21652184, https://doi.org/10.1002/qj.2513, 2015.

Stevens, B., Cotton, W. R., Feingold, G., and Moeng, C.H.: Large-eddy simulations ofstrongly precipitating, shallow, stratocumulus-topped boundary layers, J. Atmos. Sci., 55, 3616-3638, https://doi.org/10.1175/15200469(1998)055<3616:LESOSP>2.0.CO;2, 1998.

Stevens, B., Ackermann, A. S., Albrecht, B. A., Brown, A., Chlond, A., Cuxart, J., Duynkerke, P. G., Lewellen, D. C., Macvean, M. K., Neggers, R. A. J., Sanchez, E., Siebesma, A. P., and Stevens, D. E.: Simulations of trade wind cumuli under a strong inversion, J. Atmos. Sci., 58, 1870-1891, 2001.

Stevens, B., Moeng, C.-H., Ackermann, A. S., Bretherton, C. S., Chlond, A., de Roode, S., Edwards, J., Golaz, J.-C., Jiang, H., Khairoutdinov, A., Kirkpatrick, M. P., Lewellen, D. C., Lock, A., Müller, F., Stevens, D. E., Whelan, E., and Zhu, P.: Evaluation of large-eddy simulations via observations of nocturnal marine stratocumlus, Mon. Weather Rev., 133, 1443-1462, https://doi.org/10.1175/MWR2930.1, 2005.

Stevens, B., Farrell, D., Hirsch, L., Jansen, F., Nuijens, L., Brügmann, I. S., Forde, M., Linné, H., Lonitz, K., and Prospero, J. M.: The Barbados Cloud Observatory: Anchoring Investigations of Clouds and Circulation on the Edge of the ITCZ, B. Am. Meteorol. Soc., 97, 787-801, https://doi.org/10.1175/BAMS-D-14$00247.1,2016$

Stull, R. B.: An Introduction to Boundary Layer Meteorology, Kluwer Academic Springer, 666 pp., 1988.

Sühring, M. and Raasch, S.: Heterogeneity-induced heat flux patterns in the convective boundary layer: Can they be detected from observations and is there a blending height? - A large-eddy simulation study for the LITFASS-2003 experiment, Bound.-Lay. Meteorol., 148, 309-331, https://doi.org/10.1007/s10546-013-9822$1,2013$.

Taylor, G. I.: Effects of variation in density on the stability of superimposed streams of fluids, P. Roy. Soc. Lond. A, 132, 499-523, 1931.

van Stratum, B. J. H. and Stevens, B.: The influence of misrepresenting the nocturnal boundary layer on idealized daytime convection in large-eddy simulation, J. Adv. Model. Earth Syst., 7, 423-436, https://doi.org/10.1002/2014MS000370, 2015.

vanZanten, A. C., Stevens, B., Nuijens, L., Siebesma, A. P., Ackermann, A. S., Burnet, F., Cheng, A., Couvreux, F., Jiang, H., Khairoutdinov, M., Kogan, Y., Lewellen, D. C., Mechem, D., Nakamura, K., Noda, A., Shipway, B. J., Slawinska, J., Wang, S., and Wyszogrodzki, A.: Controls on precipitation 
and cloudiness in simulations of trade-wind cumulus as observed during Rico, J. Adv. Model. Earth Syst., 3, M06001, https://doi.org/10.1029/2011MS000056, 2011.

Vollmer, L., van Dooren, M., Trabucchi, D., Schneemann, J., Steinfeld, G., Witha, B., Trujillo, J., and Kühn, M.: First comparison of LES of an offshore wind turbine wake with dual-Doppler lidar measurements in a German offshore wind farm, J. Phys. Conf. Ser., 625, 012001, http://stacks.iop.org/1742-6596/625/i= $1 / \mathrm{a}=012001,2015$.

Wicker, L. J. and Skamarock, W. S.: Time-splitting methods for elastic models using forward time schemes, J. Atmos. Sci., 130, 2088-2097, https://doi.org/10.1175/15200493(2002)130<2088:TSMFEM>2.0.CO;2, 2002.

Wulfmeyer, D., Muppa, S., Behrendt, A., Hammann, E., Späth, F., Sorbjan, Z., Turner, D., and Hardesty, R.: Determination of the convective boundary layer entrianment fluxes, dissipation rates and the molecular destruction of variances: Theoretical descritpion and a strategy for its confirmation with a novel lidar system synergy, J. Atmos. Sci., 73, 667-692, https://doi.org/10.1175/JAS-D-14-0392.1, 2016.
Wulfmeyer, V., Hardesty, R. M., Turner, D. D., Behrendt, A., Cadeddu, M. P., Girolamo, P. D., Schlüssel, P., Baelen, J. V., and Zus, F.: A review of the remote sensing of lower-tropospheric thermodynamic profiles and its indispensable role for the understanding and the simulation of water and energy cycles, Rev. Geophys., 53, 819-895, https://doi.org/10.1002/2014RG000476, 2015.

Zacharias, S., Bogena, H., Samaniego, L., Mauder, M., Fuß, R., Pütz, T., Frenzel, M., Schwank, M., Baessler, C., ButterbachBahl, K., Bens, O., Borg, E., Brauer, A., Dietrich, P., Hajnsek, I., Helle, G., Kiese, R., Kunstmann, H., Klotz, S., Munch, J. C., Papen, H., Priesack, E., Schmid, H. P., Steinbrecher, R., Rosenbaum, U., Teutsch, G., and Vereecken, H.: A network of terrestrial environmental observatories in Germany, Vadose Zone J., 10, 955-973, https://doi.org/10.2136/vzj2010.0139, 2011.

Zilitinkevich, S. and Baklanov, A.: Calculation of the height of the stable boundary layer in practical applications, Bound.-Lay. Meteorol., 105, 389-409, https://doi.org/10.1023/A:1020376832738, 2002. 